FELIPE FERNANDES DE CARVALHO

\title{
A CONFORMAÇÃO DA CEGUEIRA DELIBERADA NO DIREITO PENAL BRASILEIRO
}

\author{
Dissertação de Mestrado \\ Orientador: Professor Associado Pierpaolo Cruz Bottini
}

UNIVERSIDADE DE SÃO PAULO

FACULDADE DE DIREITO

São Paulo

2019 


\section{A CONFORMAÇÃO DA CEGUEIRA DELIBERADA NO DIREITO PENAL BRASILEIRO}

Dissertação apresentada à Banca Examinadora do Programa de Pós-Graduação em Direito da Faculdade de Direito da Universidade de São Paulo, para obtenção do título de Mestre em Direito Penal, Criminologia e Medicina Forense, sob a orientação do Professor Associado Pierpaolo Cruz Bottini.

UNIVERSIDADE DE SÃO PAULO

FACULDADE DE DIREITO

São Paulo 


\section{A CONFORMAÇÃO DA CEGUEIRA DELIBERADA NO DIREITO PENAL BRASILEIRO}

Dissertação apresentada à Banca Examinadora do Programa de Pós-Graduação em Direito da Faculdade de Direito da Universidade de São Paulo, para obtenção do título de Mestre em Direito Penal, Criminologia e Medicina Forense, sob a orientação do Professor Associado Pierpaolo Cruz Bottini.

Aprovada em: de de 2019. 


\section{AGRADECIMENTOS}

Este trabalho foi concebido e desenvolvido a partir de uma série de experiências acadêmicas, profissionais e pessoais, mas apenas foi possível pelo suporte que me foi dado por minha família e amigos. Reconcebi, a partir do contato com vocês, os conceitos de apoio, incentivo e perseverança.

Portanto, aos meus pais, Gisele e Stenio, sou grato pelo carinho, amor e atenção, que nunca foram dispensados mesmo em momentos de dificuldades. Devo a vocês e a meus avôs tudo o que sou hoje e tudo o que serei amanhã.

À Mariana, minha Amora, cujo companheirismo me cercou durante esses anos de estudo e que certamente me cercará por toda minha vida, agradeço pelo amor, afeto, paciência e abnegação. Foi com você que conversei diariamente sobre este estudo, minhas dúvidas, minhas respostas e minhas angústias. E, tendo sido concluído este trabalho, é com você que continuarei a minha jornada.

Ao Guilherme e à Lívia, obrigado por me emprestarem um lugar para chamar de casa em São Paulo e que, durante esses anos de estudo, encheram-me de alegria, sobretudo com o nascimento da Maria Clara. Este trabalho teria sido muito mais árduo sem vocês e sem a companhia e parceria do Gustavo.

Ao Professor Pierpaolo Bottini, que me orientou nesta pesquisa de quase três anos, e ao Professor José Carlos Porciúncula Neto, que foi o primeiro a me instigar a estudar a cegueira deliberada, agradeço pelos ensinamentos, provocações e instigações. Devo a vocês incontáveis aprendizados. Aos demais Professores das Arcadas do Largo São Francisco, obrigado pela acolhida e por viabilizar que essa renomada Faculdade se transformasse em minha nova casa acadêmica.

Ao amigo Rodrigo Mudrovitsch, sou grato pelas oportunidades que me permitiram ter os primeiros contatos com o tema debatido neste trabalho, bem como pelas tantas conversas que tivemos sobre este e tantos outros assuntos do Direito Penal.

Aos demais amigos que me acompanharam nessa trajetória, agradeço por desfrutarmos juntos momentos de alegria e por terem sido tão compreensivos por momentos em que me ausentei em função dos estudos.

A todos vocês, muito obrigado. 


\section{RESUMO}

CARVALHO, Felipe Fernandes de. A conformação da cegueira deliberada no direito penal brasileiro. 2019. 216 p. Dissertação (Mestrado em Direito Penal, Criminologia e Medicina Forense) - Faculdade de Direito, Universidade de São Paulo, São Paulo, 2019.

A despeito de originada no direito estadunidense, a cegueira deliberada tem sido cada vez mais utilizada em decisões judiciais brasileiras. Objetivando compreender a sua conformação no direito brasileiro, elucida-se a forma como é aplicada e utilizada na Justiça Federal estadunidense, analisam-se nove teorias do dolo que baseiam a dogmática romanogermânica, sobre a qual o direito brasileiro foi erigido, e examinam-se todos os acórdãos de mérito proferidos até a data de 01/05/2019 pela Justiça Federal brasileira, que abordam a cegueira deliberada. Neste estudo, constata-se que a cegueira deliberada é conceituada de várias formas pela jurisprudência estadunidense. A diversidade de acepções da cegueira deliberada não foi identificada quando do exame dos casos julgados pela Justiça Federal brasileira. Por sua vez, as teorias do dolo não contemplam de forma natural o núcleo duro do conceito de cegueira deliberada. Nos casos analisados pela Justiça Federal brasileira, assim como em outros mencionados pela doutrina, foram poucos aqueles que justificaram de forma adequada a sua utilização, levando em consideração o arcabouço dogmático já existente. Sob o espeque da teoria do consentimento, consubstancia indicativo da existência de dolo a decisão do acusado de manter-se inerte quanto à tomada de conhecimento de circunstância essencial para a configuração de um delito, quando houver alta probabilidade de ocorrência dessa circunstância.

Palavras-chave: Cegueira deliberada. Dolo. Dolo eventual. 


\begin{abstract}
CARVALHO, Felipe Fernandes de. The frame of willful blindness in brazilian criminal law. 2019. 216 p. LLM paper (LLM in Criminal Law, Criminology and Forensic Medicine) Faculty of Law, University of São Paulo, São Paulo, 2019.

Despite its American law origins, Brazilian courts have been increasingly using the willful blindness concept in their decisions. With the aim of understanding how this concept has been incorporated into Brazilian law, this paper analyzes nine theories of criminal intent that underlie the Civil Law system, in which Brazilian law is grounded, and examines all judgments on the merits issued by Brazilian Federal Courts that, until May 1, 2019, addressed willful blindness. The study finds that American case law understands willful blindness in a variety of ways. This diversity was not identified in the cases that Brazilian Federal Courts judged. In turn, criminal intent theories do not consider the core elements of the concept of willful blindness. Amongst the cases judged by Brazilian Federal Courts, as well as others studied by legal scholars, only a few properly justified the use of willful blindness in line with the existing doctrinal framework. Under the theory of consent, the defendant's decision to remain inert after the knowledge of a key element to the configuration of a crime indicates the existence of criminal intent, when the occurrence of this element is highly probable.
\end{abstract}

Keywords: Willful blindness. Criminal intent. Assumption of risk. 


\section{SUMÁRIO}

1. INTRODUÇÃO

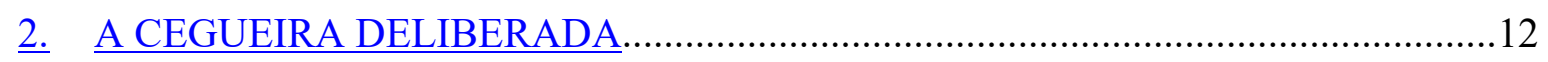

2.1 A origem da cegueira deliberada................................................................. 15

$\underline{2.2}$ As culpabilities do sistema estadunidense ........................................................ 24

3. AS CARACTERÍSTICAS DO ELEMENTO SUBJETIVO NA DOGMÁTICA

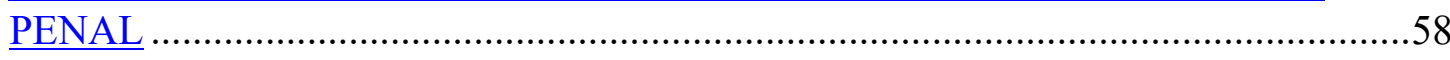

3.1 As teorias do dolo no sistema romano-germânico: o dolo direto, o dolo de

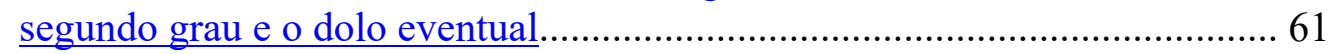

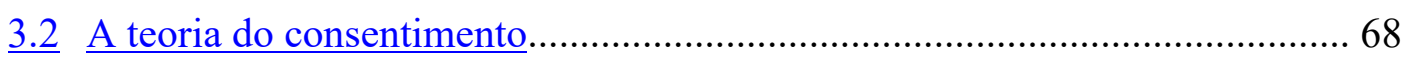

$\underline{3.3}$ A teoria da indiferença ................................................................................. 75

$\underline{3.4}$ A teoria da possibilidade ................................................................................. 79

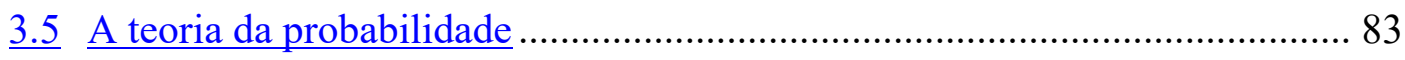

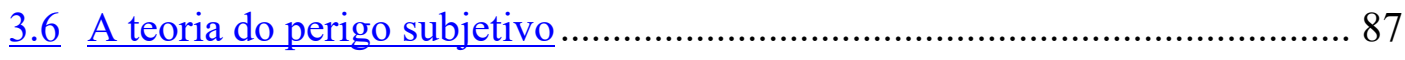

3.7 A teoria do perigo objetivo.............................................................................. 90

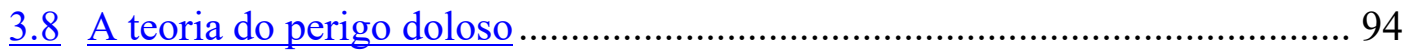

4. A INTROJEÇÃO DA CEGUEIRA DELIBERADA NOS SISTEMAS ROMANO-

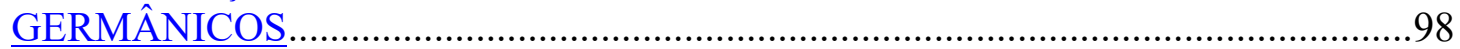

4.1 A análise de precedentes da Justiça Federal brasileira que invocam a cegueira deliberada ................................................................................................ 103

$\underline{4.2}$ A resolução de outros casos concretos .......................................................... 148

4.2.1 A resolução de casos doutrinários ………………………………..... 150

4.2.2 A resolução de casos da jurisprudência estadunidense: United States v. Jewell e Heredia v. United States...................................................... 162

4.3 A relação dos elementos da cegueira deliberada e as teorias do dolo............ 167

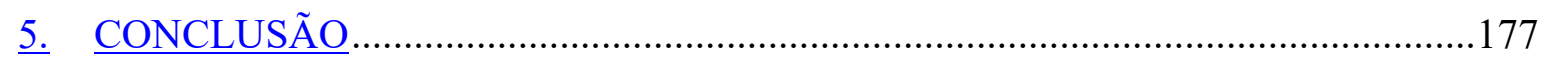




\section{INTRODUÇÃO}

Construído sob matriz romano-germânica, o Código Penal brasileiro elencou de forma expressa os requisitos para a responsabilização criminal. Como cediço, no âmbito dogmático, a responsabilização subjetiva está consagrada no direito brasileiro no artigo 18 do Código Penal, o qual estatui os elementos básicos para a categorização de uma conduta como dolosa ou culposa.

De forma diversa, o direito penal estadunidense não apresenta matizações claras a respeito dos elementos subjetivos necessários para a configuração de um ilícito de natureza penal. Nesse sentido, no início da década de 1960, um grupo de juristas empreendeu esforços para conferir mínima padronização para a questão, elaborando uma proposta de legislação denominada Código Penal Modelo, o qual veicula quatro formas de responsabilização penal, notadamente as culpabilities purpose, knowledge, recklesness e negligence.

Sem embargo da baixa sistematização dos elementos subjetivos essenciais para a configuração de um delito sob o prisma estadunidense, Magistrados brasileiros têm, cada vez mais, utilizado a cegueira deliberada em suas decisões. Entre o ano de 2007 e setembro de 2013, foram identificados 11 acórdãos de Tribunais Regionais Federais, do Superior Tribunal de Justiça e do Supremo Tribunal Federal que a mencionaram ao longo do decisum. De outra sorte, entre setembro de 2013 e maio de 2019, foram localizados 554 acórdãos citando-a. $^{1}$

No ponto, a cegueira deliberada foi conceituada pela primeira vez a nível nacional no Código Penal Modelo e sua utilização, nos Estados Unidos, foi chancelada por vários Tribunais, inclusive pela Suprema Corte desse país. Nesse contexto, são questões essenciais para a compreensão da sua aplicação por parte dos operadores jurídicos brasileiros o exame dos pressupostos de aplicação da cegueira deliberada, de sua função dentro da sistemática erigida no Código Penal Modelo e da forma com que as Cortes estadunidenses a utilizam.

Referida análise será empreendida ao longo do primeiro capítulo deste trabalho. Para tanto, serão discriminados a origem da cegueira deliberada, os conceitos estatuídos dentro do Código Penal Modelo para a responsabilização criminal de agentes, os precedentes

1 Será exposto ao longo deste trabalho que, até 01/05/2019, foram proferidos 545 acórdãos pelo Tribunal Regional Federal da $4^{a}$ Região em que a cegueira deliberada é mencionada. 
estadunidenses a propósito do tema e as lições de doutrinadores estadunidenses acerca de sua aplicação. Como recorte do objeto do estudo, analisar-se-ão precedentes de todas as Cortes de Apelação dos Circuitos Federais dos Estados Unidos da América, bem como segmentar-se-ão os seus pressupostos de aplicação, cotejando-os com aqueles elencados pelo Código Penal Modelo e pela doutrina estadunidense.

Situado o estado da arte da cegueira deliberada no âmbito estadunidense e delineadas as várias acepções que esta possui nesse sistema jurídico, o trabalho buscará sedimentar as balizas nas quais o direito brasileiro fincou os seus alicerces para viabilizar a responsabilização penal. Como será demonstrado ao longo do segundo capítulo deste trabalho, malgrado o artigo 18 do Código Penal elenque os requisitos para essa finalidade, existem algumas interpretações possíveis a respeito do conceito de dolo no direito brasileiro. Nessa esteira, o segundo capítulo apresentará as balizas conceituais das principais teorias do dolo que permeiam o sistema romano-germânico e, por conseguinte, que influenciam a interpretação do conceito de dolo no Brasil.

Estabelecidas as premissas para aplicação da cegueira deliberada nos Estados Unidos da América e as possíveis matizações do dolo no Brasil, analisar-se-ão os casos concretos em que o Poder Judiciário brasileiro mencionou a cegueira deliberada. O objetivo dessa análise é compreender em que medida a cegueira deliberada é utilizada como razão de decidir em sentenças judiciais, como o Poder Judiciário tem abordado os pressupostos de aplicação da cegueira deliberada e o tratamento por ele conferido à cegueira deliberada à luz do anteparo legal e dogmático brasileiro. A partir desse exame, será possível, também, compreender a relevância da cegueira deliberada para a aferição do dolo no âmbito do Direito brasileiro.

O resultado do exame proposto evidenciará que, no âmbito estadunidense, a cegueira deliberada possui a precípua função de elevar standard probatório necessário para admissão da arguição defensiva de uma situação de erro de tipo. Com efeito, a conceituação mais aceita nos Estados Unidos da América declina que a cegueira deliberada é uma forma equiparada à culpability knowledge, a qual, para a responsabilização penal do agente, demanda, apenas, que ele tenha a consciência da existência das circunstâncias essenciais para a caracterização do delito.

Nesse espeque, as teorias do dolo sobre as quais a dogmática romano-germânica foi erigida não permitem a responsabilização criminal do agente apenas pela ciência dos elementos do tipo penal. Por essa razão, conclui-se que não é possível equiparar a cegueira 
deliberada - tal como aplicada no âmbito estadunidense - ao conceito de dolo, ainda que na modalidade eventual.

Essa conclusão também poderá ser extraída da análise dos julgados no Brasil, os quais, de uma forma geral, analisam parca e equivocadamente o conceito de cegueira deliberada, tergiversando daquelas acepções erigidas no direito estadunidense, e utilizam-na como argumentação subsidiária para a formação da convicção, sendo despicienda como ratio decidendi. No ponto, os julgados analisados revelam que a resolução dos casos concretos deriva não da invocação da cegueira deliberada, mas da análise dos elementos probatórios e indiciários a partir dos quais se deduz o dolo do agente delitivo.

Nessa direção, será possível concluir, ainda, que os elementos constitutivos da cegueira deliberada podem ser utilizados como relevantes indicativos para aferição do dolo por parte do Magistrado. Os reflexos desses elementos para a identificação do dolo dependerão do arcabouço teórico que se utiliza como parâmetro, tal como será pormenorizado no último capítulo deste trabalho. 


\section{CONCLUSÃO}

Ao longo deste trabalho, foram analisados os pressupostos de aplicação da cegueira deliberada no âmbito estadunidense, bem como o contexto no qual foi sedimentada. Como visto, a legislação dos Estados Unidos da América não declina de forma clara e ordenada os requisitos subjetivos para a responsabilização criminal. Nesse contexto, foi elaborado o Código Penal Modelo, proposta de legislação que sistematizou em quatro culpabilities os estados anímicos tidos como necessários para viabilizar a responsabilização penal.

Nesse viés, o Código Penal Modelo convencionou denominar de cegueira deliberada a equiparação à casuística em que há efetivo conhecimento fático por parte do agente - a qual corresponde à culpability knowledge - a situação em que - embora não detenha efetivo conhecimento a propósito de todas as circunstâncias necessárias para a configuração de um delito - o agente possui ciência acerca da alta probabilidade da ocorrência dessas circunstâncias. Consoante o Código Penal Modelo, apenas aqueles que efetivamente acreditem que as circunstâncias essenciais não estão presentes não podem ser responsabilizados a título de knowledge por meio da cegueira deliberada.

Nessa direção, se o agente estiver em um cenário fático a partir do qual é possível deduzir que possui conhecimento da alta probabilidade da ocorrência das circunstâncias essenciais para caracterização do delito, deverá ele ser penalizado ainda que não tenha efetiva ciência a respeito delas - salvo se for provado que efetivamente não acreditava na ocorrência das circunstâncias. Por esse prisma, a cegueira deliberada estabelece, na sistemática do Código Penal Modelo, uma cláusula de elevação do standard probatório para admissão da arguição defensiva de erro de tipo.

Conquanto seja essa a disposição do Código Penal Modelo, foi evidenciado que a jurisprudência estadunidense agregou ao conceito de cegueira deliberada a necessidade de o agente tomar a decisão de não aprofundar o seu conhecimento a respeito do plano fático. Nessa perspectiva, para a penalização do agente a título de dolo, não basta que este esteja diante de um cenário em que se deduz a sua ciência da alta probabilidade das circunstâncias essenciais, devendo-se aferir, ainda, a sua decisão de não aprofundar o seu conhecimento a respeito delas. 
Foi evidenciado, ademais, que parcela minoritária das Cortes de Apelação dos Circuitos Federais - assim como a doutrina estadunidense - demandam, para configuração da cegueira deliberada, um requisito adicional, notadamente a motivação do agente que o levou a não aprofundar seu conhecimento sobre as circunstâncias essenciais para configuração do delito. Para essa acepção da cegueira deliberada, a punição de um agente a título de knowledge somente será possível quando a conduta por ele executada em cegueira deliberada for igualmente reprovável a uma conduta praticada em situação de conhecimento pleno. Nessa esteira, apontou-se que, para esse segmento interpretativo, a reprovabilidade da conduta do agente depende da legitimidade de sua motivação para quedar-se inerte.

Conforme visto dos casos julgados pelas cortes federais brasileiras, por via de regra, passa-se ao largo da indicação da vertente da cegueira deliberada que se pretende utilizar e, por conseguinte, da fundamentação das razões que levaram a optar por uma acepção em detrimento das outras. No ponto, foi possível classificar os casos analisados em três grupos, sendo que, da análise de um deles, extraiu-se clara dificuldade de se introduzir conceito alienígena erigido na common law em sistema calcado no modelo romanogermânico. Nesse grupo, a invocação da cegueira deliberada ocorreu de forma desconexa a qualquer objetivo ou justificativa aparente.

Do exame dos outros dois grupos de casos, foi possível obter relevantes conclusões. Naqueles casos em que a utilização da cegueira deliberada se mostrou desnecessária enquanto ratio decidendi, concluiu-se que o fator decisivo para a prolação da decisão foram os elementos concretos que estavam carreados aos autos, a partir dos quais deduziu-se o conhecimento efetivo do agente sobre o plano fático. Nessa perspectiva, afigurou-se contraditória a utilização da cegueira deliberada nessas sentenças ou votos - na medida em que ela foi delineada nos Estados Unidos da América para situações em que o agente não possui conhecimento efetivo.

Já no outro grupo, os pressupostos de aplicação da cegueira deliberada foram utilizados como elementos indicativos da existência de dolo por parte do agente delitivo em um caso concreto. Nesse conjunto, foram utilizados os requisitos da acepção mais comum da cegueira deliberada nos Estados Unidos da América para fundamentar a existência de dolo por parte do agente - a saber, a ciência por parte do agente da alta probabilidade da ocorrência das circunstâncias essenciais para a caracterização de um delito e a sua decisão por não aprofundar seu conhecimento. 
No ponto, identificou-se que a relevância desses dois requisitos para viabilizar referido exame depende do parâmetro conceitual de dolo que se utiliza. No que atine às teorias de disposição de ânimo estudadas, notadamente as teorias do consentimento e da indiferença, a decisão do agente de não aprofundar o seu conhecimento a respeito do plano fático pode ser um indicativo de que tinha ciência das circunstâncias essenciais para a configuração do delito e que anuiu para a produção da lesão à norma jurídica.

Referida análise pode ser transportada quando do cotejo dos elementos constitutivos da cegueira deliberada para a teoria do perigo subjetivo. Porquanto acaba por repristinar alguns aspectos da imputação da teoria do consentimento, a decisão do agente de não aprofundar o conhecimento do plano fático pode, como demonstrado, viabilizar a aferição do barema subjetivo de que trata a conceituação de Frisch.

Tomando como parâmetro teorias do dolo cognitivistas, ressaltou-se que seria possível cogitar uma maior proximidade com o conceito de cegueira deliberada. Sem embargo, referida hipótese encontra-se equivocada. Especificamente quanto às teorias da possibilidade e da probabilidade, a forma como que cunham o dolo é diversa do modo como a cegueira deliberada viabiliza a imputação a título de conhecimento no sistema estadunidense. O critério que diferencia o dolo da culpa para ambas as teorias não é a relação de conhecimento do agente para com o plano fático - certo que esse requisito é um pressuposto para a imputação subjetiva -, mas a relação de sua representação com a produção do resultado naturalístico. Os referenciais de que a cegueira deliberada e as teorias da possibilidade e probabilidade abordam são, portanto, distintos. Mais do que isso, demonstrou-se que, sob esses prismas, a decisão do agente de não aprofundar seu conhecimento a respeito da efetiva existência de circunstâncias essenciais ao tipo penal é irrelevante para a aferição do dolo ou da culpa sob a égide dessas teorias.

Por fim, quanto às teorias do perigo objetiva e dolosa, evidenciaram-se a ausência de interação entre os conceitos por elas abordados e os requisitos da cegueira deliberada, tal como delineada nos Estados Unidos da América. Nessa esteira, restou demonstrado que as teorizações do dolo sob a perspectiva romano-germânica são mais abrangentes que o conceito de cegueira deliberada - tal como delineado no âmbito dos Estados Unidos da América. No ponto, não foi possível identificar casos em que a suplantação de lacunas de punibilidade pudesse ser realizada pela cegueira deliberada e não pelos conceitos de dolo eventual. 
Assim, conclui-se que a cegueira deliberada, enquanto conceito, não se mostra útil dentro do sistema jurídico brasileiro. De outra sorte, demonstrou-se que os seus elementos constitutivos podem ser relevantes indicativos a respeito da existência do dolo por parte do agente em um caso concreto.

$\mathrm{Na}$ medida em que majoritariamente se concebe o dolo sob a ótica da teoria do consentimento, a aferição da decisão do agente de não aprofundar seu conhecimento a respeito do plano fático pode ser utilizado como parâmetro para identificação do dolo no caso concreto. Sem embargo, a identificação desse requisito em um caso concreto não implica o reconhecimento do dolo do agente, mas apenas um indicativo de sua presença. Com efeito, a motivação do agente em quedar-se inerte e os demais elementos indiciários que circundam o caso necessitam ser avaliados para classificação da conduta como dolosa ou culposa. 


\section{REFERÊNCIAS BIBLIOGRÁFICAS}

ALEMANHA. Código Penal. Código Penal, de 13 de novembro de 1998. Disponível em: $<$ https://ec.europa.eu/anti-trafficking/sites/antitrafficking/files/criminal_code_ germany_en_1.pdf>. Acesso em: 12 fev. 2019. 1998.

ASÚA, Luis Jiménez. Tratado de derecho penal 3. Buenos aires: Losada, 1964.

AMERICAN LAW INSTITUTE. Filadélfia, Estados Unidos da América. Disponível em: $<$ https://www.ali.org/>. Acesso em: 12 fev. 2019.

AWARENESS, Oxford Living Dictionaries. Disponível em: $<$ https://en.oxforddictionaries.com/definition/awareness>. Acesso em: 10 fev. 2019.

BADARÓ, Jennifer Falk. Dolo no crime de lavagem de dinheiro. Belo Horizonte: Editora D’Plácido, 2018;

BECK, Ulrich. La Sociedad del Riesgo Global. Madrid: Siglo Veitiuno, 2002.

BLANCO CORDERO, Isidoro. El delito de blanqueo de capitales. 3. ed. Navarra: Arazandi, 2013.

BORJA JIMENEZ, Emiliano. Algunos planteamientos dogmáticos en la teoría jurídica del delito en Alemania, Italia, y España. Cuadernos de política criminal, ISSN 0210-4059, n. 63, 1997.

BOTTINI, Pierpaolo Cruz. O paradoxo do risco e a política criminal contemporânea. In: MENDES, Gilmar Ferreira; BOTTINI, Pierpaolo Cruz; PACELLI, Eugênio (Coord.). Direito penal contemporâneo. Questões controversas. São Paulo: Saraiva, 2011.

BOTTINI, Pierpaolo Cruz; BADARÓ, Gustavo Henrique. Lavagem de dinheiro: aspectos penais e processuais penais: comentários à Lei 9.613/1998, com alterações da Lei 12.683/2012. São Paulo: Revista dos Tribunais, 2012.

BOTTINI, Pierpaolo Cruz. Crimes de perigo abstrato. 3. ed. rev. e atual. São Paulo: Revista dos Tribunais, 2013-A.

BOTTINI, Pierpaolo Cruz. Lavagem de dinheiro na Apn 470/MG. Revista dos Tribunais, v. 933/2013, p. 383-400, 2013-B.

BRASIL, Código Penal. Decreto-Lei n. 2.848, de 7 de dezembro de 1940. Disponível em: $<$ http://www.planalto.gov.br/ccivil_03/decreto-lei/del2848compilado.htm>. Acesso em: 12 fev. 2019. 1940. 
BRASIL, Lei Federal n. 8.137/1990, de 27 de dezembro de 1990. Disponível em: $<$ http://www.planalto.gov.br/ccivil_03/LEIS/L8137.htm>. 12 fev. 2019. 1990.

BRASIL. Lei Federal n. 8.666/1993, de 21 de junho de 1993. Disponível em: <http://www.planalto.gov.br/ccivil_03/LEIS/L8666cons.htm>. 12 fev. 2019. 1993.

BRASIL. Exposição de Motivos 692/MJ, de 18 de dezembro de 1998. Disponível em: $<$ http://fazenda.gov.br/orgaos/coaf/legislacao-e-normas/legislacao/exposicao-demotivos-lei9613.pdf/@@download/file/Exposicao\%20de\%20Motivos\%20Lei\%209613.pdf>. Acesso em: 16 abr. 2019. 1996.

BRASIL. Lei Federal n. 9.613/1998, de 3 de março de 1998. Disponível em: $<$ http://www.planalto.gov.br/ccivil_03/leis/19613.htm>. 12 fev. 2019. 1998.

BRASIL. Seção Judiciária do Ceará. Ação Penal n. 200581000145860. Magistrado Danilo Fontenelle Sampaio, Fortaleza, 2007.

BRASIL. Supremo Tribunal Federal. Habeas Corpus n. 92.304. Relatora Ministra Ellen Gracie, Segunda Turma. Julgamento em 05/08/2008, Brasília, 2008-A.

BRASIL. Tribunal Regional Federal, Região 5. Apelação Criminal n. 200581000145860. Relator Desembargador Federal Rogério Fialho Moreira, Segunda Turma. Julgamento em 09/09/2008, Recife, 2008-B.

BRASIL. Lei Federal n. 12.683/2012, de 9 de julho de 2012. Disponível em: $<$ http://www.planalto.gov.br/ccivil_03/_Ato2011-2014/2012/Lei/L12683.htm\#art2>. Acesso em: 16 abr. 2019. 2012-A.

BRASIL. Senado Federal. Projeto de Lei do Senado n. 236/2012. Projeto de Reforma do Código Penal, altera o Decreto-Lei n. 2.848, de 7 de dezembro de 1940. Disponível em: $<$ https://www25.senado.leg.br/web/atividade/materias/-/materia/106404>. Acesso em: 16 abr. 2019. 2012-B.

BRASIL. Supremo Tribunal Federal. Ação Penal n. 470. Relator Ministro Joaquim Barbosa, Plenário. Brasília, 2013-A.

BRASIL. Tribunal Regional Federal, Região 4. Apelação Criminal n. 50097228120114047002. Relator Juiz Convocado Sergio Fernando Moro, Oitava Turma. Julgamento em 23/09/2013, Porto Alegre, 2013-B.

BRASIL. Seção Judiciária de Curitiba. Ação Penal n. 5025687032014047000. Magistrado Sergio Moro, Curitiba, 2014-A. 
BRASIL. Tribunal Regional Federal, Região 2. Apelação Criminal n. 00013741920094025117. Relator Desembargador Federal Antonio Ivan Athié. Julgamento em 07/05/2014, Rio de Janeiro, 2014-B.

BRASIL. Tribunal Regional Federal, Região 3. Apelação Criminal n. 00100176220124036109. Relator Desembargador Federal José Lunardelli, Décima Primeira Turma. Julgamento em 16/12/2014, São Paulo, 2014-C.

BRASIL. Seção Judiciária de Curitiba. Ação Penal n. 50231353120154047000 . Magistrado Sergio Moro, Curitiba, 2015-A.

BRASIL. Seção Judiciária de Curitiba. Ação Penal n. 50472297720144047000 . Magistrado Sergio Moro, Curitiba, 2015-B.

BRASIL. Tribunal Regional Federal, Região 3. Apelação Criminal n. 00062518620064036181. Relator Desembargador Federal Hélio Nogueira, Quinta Turma. Julgamento em 23/03/2015, São Paulo, 2015-C.

BRASIL. Tribunal Regional Federal, Região 5. Apelação Criminal n. 00111923120104058300. Relator Desembargador Federal Emiliano Zapata Leitão, Quarta Turma. Julgamento em 21/07/2015, Recife, 2015-D.

BRASIL. Tribunal Regional Federal, Região 3. Apelação Criminal n. 00403674720004030000. Relator Desembargador Federal Nino Toldo, Décima Primeira Turma. Julgamento em 04/08/2015, São Paulo, 2015-E.

BRASIL. Tribunal Regional Federal, Região 3. Apelação Criminal n. 00011231720084036181. Juíza Convocada Denise Avelar, Segunda Turma. Julgamento em 01/12/2015, São Paulo, 2015-F.

BRASIL. Tribunal Regional Federal, Região 5. Apelação Criminal n. 00133264420134058100. Relator Desembargador Federal Flávio Lima, Primeira Turma. Julgamento em 18/12/2015, Recife, 2015-G.

BRASIL. Seção Judiciária de Curitiba. Ação Penal N. 50276853520164047000 . Julgamento em 25/05/2016. Magistrado Sergio Moro, Curitiba, 2016-A.

BRASIL. Seção Judiciária do Rio de Janeiro. Ação Penal n. 05109268620154025101. Julgamento em 03/08/2016. Magistrado Marcelo Bretas, Rio de Janeiro, 2016-B.

BRASIL. Tribunal Regional Federal, Região 5. Apelação Criminal n. 200480000071145. Relator Desembargador Federal Ivan Lira De Carvalho, Segunda Turma. Julgamento em 09/08/2016, Recife, 2016-C.

BRASIL. Seção Judiciária de Curitiba. Ação Penal N. 50134055920164047000 . Julgamento em 02/02/2017. Magistrado Sergio Moro, Curitiba, 2017-A. 
BRASIL. Tribunal Regional Federal, Região 1. Habeas Corpus n. 00701118220164010000. Relator Desembargador Federal Ney Bello, Terceira Turma. Julgamento em 04/04/2017, Brasília, 2017-B.

BRASIL. Seção Judiciária de Curitiba. Ação Penal N. 50465129420164047000 . Julgamento em 12/07/2017. Magistrado Sergio Moro, Curitiba, 2017-C.

BRASIL. Supremo Tribunal Federal. Ação Penal n. 975. Julgamento em 03/10/2017. Relator Ministro Luiz Edson Fachin, Segunda Turma. Brasília, 2017-D.

BRASIL. Superior Tribunal de Justiça. Recurso Especial n. 1677380. Julgamento em 10/10/2017. Relator Ministro Herman Benjamin, Segunda Turma. Brasília, 2017-E.

BRASIL. Seção Judiciária do Rio de Janeiro. Ação Penal N. 01005117520164025101. Julgamento em 27/10/2017. Magistrado Marcelo Bretas, Rio de Janeiro, 2017-F.

BRASIL. Seção Judiciária do Rio de Janeiro. Ação Penal n. 05044462420174025101. Julgamento em 31/10/2017. Magistrado Marcelo Bretas, Rio de Janeiro, 2017-G.

BRASIL. Tribunal Regional Federal, Região 3. Apelação Criminal n. 00140321320164036181. Relator Desembargador Federal Mauricio Kato, Quinta Turma. Julgamento em 27/11/2017, São Paulo, 2017-H.

BRASIL. Seção Judiciária do Rio de Janeiro. Ação Penal n. 0135964-97.2017.4.02.5101. Julgamento em 02/03/2018. Magistrado Marcelo Bretas, Rio de Janeiro, 2018-A.

BRASIL. Superior Tribunal de Justiça. Agravo Regimental no Recurso Especial N. 1669311. Julgamento em 15/05/2018. Relator Ministro Jorge Mussi, Quinta Turma. Brasília, 2018-B.

BRASIL. Tribunal Regional Federal, Região 2. Apelação Criminal n. 08022071320134025101. Relator Desembargador Federal Paulo Espírito Santo, I Turma Especializada. Julgamento em 06/06/2018, Rio de Janeiro, 2018-C.

BRASIL. Tribunal Regional Federal, Região 5. Apelação Cível N. 00058476320144058100. Relator Desembargador Federal Rubens Canuto, I Turma Especializada. Julgamento em 14/08/2018, Recife, 2018-D.

BRASIL. Tribunal Regional Federal, Região 3. Apelação Criminal n. 00039125220054036000. Relator Desembargador Federal Fausto Martin de Sanctis, Décima Primeira Turma. Julgamento em 24/10/2018, São Paulo, 2018-E.

BRASIL. Tribunal Regional Federal, Região 4. Apelação Criminal n. 50141709320174047000. Relator Desembargador Federal João Pedro Gebran Neto, Décima Primeira Turma. Julgamento em 08/04/2019, Porto Alegre, 2019. 
BUJAN PÉREZ, Carlos Martínez. Derecho Penal Económico y de la Empresa. Parte General. 5. ed. Valencia: Tirant lo Blanch, 2015.

BURGEL, Letícia. A teoria da cegueira deliberada na Ação Penal 470. Revista Brasileira de Ciências Criminais, v. 129, 2017.

BUSATO, Paulo César. Dolo e significado. In: BUSATO, Paulo César (org.). Dolo e direito penal: modernas tendências. 2. ed. São Paulo: Atlas, 2014.

CALCÓTE, Sarah. Criminal Intent in Federal Environmental Statutes: What Corporate Officers and Employees Should Know. American Journal of Criminal Law 20, 19921993.

CALLEGARI, André Luís. O erro de tipo no delito de lavagem de dinheiro. Revista IberoAmericana de Ciências Penais, n. 5, v. 3, p. 37-42, 2002.

CALLEGARI, André Luís; LYNETT, Eduardo Montealegre; JAKOBS, Gunther; MELIÁ, Manuel Cancio. Direito penal e funcionalismo. Porto Alegre: Livraria do Advogado, 2005.

CALLEGARI, André Luís. Teoria geral do delito e da imputação objetiva. 3. ed. rev. e ampl. São Paulo: Atlas, 2014-A.

CALLEGARI, André Luís; WEBER, Ariel Barazzetti. Lavagem de dinheiro. São Paulo: Atlas, 2014-B.

CALLEGARI, André Luís; WEBER, Ariel Barazzetti. A cegueira deliberada da common law à civil law e a apropriação (indébita) da teoria pelo Judiciário: nova oportunidade ao ativismo judicial e o retorno à jurisprudência dos valores. Revista Brasileira de Ciências Criminais, v. 133, 2017.

CARO-JOHN, José Antonio. La normativización del Tipo Subjetivo en El Ejemplo Del Dolo. Derecho \& Sociedad, n. 39, 2012.

CARPENTIERI, José Rafael. História crítica do direito penal. Porto Alegre: Sérgio Antonio Fabris, 2012.

CHAMON JÚNIOR, Lúcio Antônio. Do giro finalista ao funcionalismo penal: embates de perspectivas dogmáticas decadentes. Porto Alegre: Sergio Antonio Fabris, 2004.

CHARLOW, Robin. Wilful Ignorance and Criminal Culpability. TLR, 70, 1992.

DE CARLI, Carla Veríssimo. Lavagem de dinheiro: ideologia da criminalização e análise do discurso. Dissertação (Mestrado) - Faculdade de Direito, PUCRS, 2006. Orientador Prof. Dr. Aury Lopes Jr., 2006. 
DÍAZ PITA, María del Mar. A presumida inexistência do elemento volitivo no dolo e sua impossibilidade de normativização. In: BUSATO, Paulo César (org.). Dolo e direito penal: modernas tendências. 2. ed. São Paulo: Atlas, 2014.

DÍEZ RIPOLLÉS, José Luis. Los elementos subjetivos del delito. Valencia: Tirant lo Blanch, 1990.

DUBBER, Markus D. An introduction to the Model Penal Code. 2. ed. New York: Oxford, 2015.

ESPANHA. Código Penal. Ley Orgánica 10/1995, de 23 de novembro de 1995. Disponível em:

$<$ https://www.boe.es/legislacion/codigos/abrir_pdf.php?fich=038_Codigo_Penal_y_leg islacion_complementaria.pdf $>$. Acesso em: 16 abr. 2019. 1995.

ESTADOS UNIDOS DA AMÉRICA. Suprema Corte dos Estados Unidos da América. N. do recurso: $107 \quad$ U.S. $126 . \quad$ Disponível em: $<$ https://supreme.justia.com/cases/federal/us/107/126/>. Julgado em: 15 de janeiro de 1883. Acesso em: 16 abr. 2019. 1883.

ESTADOS UNIDOS DA AMÉRICA. Suprema Corte dos Estados Unidos da América. N. do recurso: 174 U.S. $728 . \quad$ Disponível em: $<$ https://supreme.justia.com/cases/federal/us/174/728/>. Julgado em: 22 de maio de 1899. Acesso em: 16 abr. 2019. 1899.

ESTADOS UNIDOS DA AMÉRICA. Suprema Corte dos Estados Unidos da América. N. do recurso: $342 \quad$ U.S. 246.2 Disponível em: $<$ https://supreme.justia.com/cases/federal/us/342/246/>. Julgado em: 7 de janeiro de 1952. Acesso em: 16 abr. 2019. 1952.

ESTADOS UNIDOS DA AMÉRICA. Suprema Corte dos Estados Unidos da América. N. do recurso: 377 U.S. $476 . \quad$ Disponível em: $<$ https://supreme.justia.com/cases/federal/us/377/476/>. Julgado em: 8 de junho de 1964. Acesso em: 16 abr. 2019. 1964.

ESTADOS UNIDOS DA AMÉRICA. Suprema Corte dos Estados Unidos da América. N. do recurso: $395 \quad$ U.S. $6 . \quad$ Disponível em: $<$ https://supreme.justia.com/cases/federal/us/395/6/>. Julgado em 19 de maio de 1969. Acesso em: 16 abr. 2019. 1969.

ESTADOS UNIDOS DA AMÉRICA. Suprema Corte dos Estados Unidos da América. N. do recurso: 396 U.S. $398 . \quad$ Disponível em: $<$ https://supreme.justia.com/cases/federal/us/396/398/>. Julgado em 20 de janeiro de 1970. Acesso em: 16 abr. 2019. 1970. 
ESTADOS UNIDOS DA AMÉRICA. Corte de Apelação do Nono Circuito Federal. N. do recurso: 532 F.2D 697. Disponível em: <https://law.justia.com/cases/federal/appellatecourts/F2/532/697/99156/>. Julgado em: 27 de fevereiro de 1976. Acesso em: 16 abr. 2019. 1976.

ESTADOS UNIDOS DA AMÉRICA. Corte de Apelação do Nono Circuito Federal. N. do recurso: 688 F.2d 607. Apelante Miguel Garzón. Disponível em: $<$ https://www.courtlistener.com/opinion/408228/united-states-v-miguel-garzon/>. Julgado em 20 de setembro de 1982. Acesso em: 16 abr. 2019. 1982.

ESTADOS UNIDOS DA AMÉRICA. Corte de Apelação do Quarto Circuito Federal. N. do recurso: 773 F.2d 579. Apelante George Martin. Disponível em: $<$ https://casetext.com/case/united-states-v-martin-112>. Julgado em 25 de setembro de 1985. Acesso em: 16 abr. 2019. 1985.

ESTADOS UNIDOS DA AMÉRICA. Corte de Apelação do Nono Circuito Federal. N. do recurso: 838 F.2d311. Apelante: Gustavo Alvarado. Disponível em: $<$ https://casetext.com/case/us-v-alvarado-9>. Julgado em 18 de maio de 1987. Acesso em: 16 abr. 2019. 1987.

ESTADOS UNIDOS DA AMÉRICA. Corte de Apelação do Oitavo Circuito Federal. N. do recurso: 979 F.2d 647. Apelante: Gary Barnhart. Disponível em: $<$ https://casetext.com/case/us-v-barnhart-2>. Julgado em 10 de novembro de 1992. Acesso em: 16 abr. 2019. 1992.

ESTADOS UNIDOS DA AMÉRICA. Corte de Apelação do Décimo Circuito Federal. N. do recurso: 99-2188. Apelante: José G. Delreal-Ordones. Disponível em: $<$ http://caselaw.findlaw.com/us-10th-circuit/1014016.html $>$. Julgado em 30 de maio de 2000. Acesso em: 16 abr. 2019. 2000.

ESTADOS UNIDOS DA AMÉRICA. Corte de Apelação do Oitavo Circuito Federal. N. do recurso: 01-2912. Apelante: Charles A. Willis. Disponível em: $<$ http://caselaw.findlaw.com/us-8th-circuit/1019462.html $>$. Julgado em 24 de janeiro 2002. Acesso em: 16 abr. 2019. 2002.

ESTADOS UNIDOS DA AMÉRICA. Corte de Apelação do Quinto Circuito Federal. N. do recurso: 02-400978. Apelantes: Estados Unidos da América e Juan Arturo MendozaMedina. Disponível em: <http://caselaw.findlaw.com/us-5th-circuit/1371004.html>. Julgado em 10 de setembro de 2003. Acesso em: 16 abr. 2019. 2003-A.

ESTADOS UNIDOS DA AMÉRICA. Corte de Apelação do Segundo Circuito Federal. N. do recurso: 03-1102. Apelante: Estados Unidos da América e Richard A. Svoboda. Disponível em: $<$ http://caselaw.findlaw.com/us-2nd-circuit/1227159.html $>$. Julgado em 24 de outubro de 2003. Acesso em: 16 abr. 2019. 2003-B. 
ESTADOS UNIDOS DA AMÉRICA. Corte de Apelação do Décimo Primeiro Circuito Federal. N. dos recursos: 02-12605, 021606 e 02-14586. Apelantes: Estados Unidos da América, Mauricio Javier Puche, Enrique Alfonso Puche e Gloria Exchange Corporation. Disponível em: <http://caselaw.findlaw.com/us-10thcircuit/1014016.html>. Julgado em 12 de novembro de 2003. Acesso em: 16 abr. 2019. 2003-C.

ESTADOS UNIDOS DA AMÉRICA. Corte de Apelação do Quinto Circuito Federal. N. do recurso: 04-30037. Apelante: Jerry Freeman. Disponível em: $<$ https://www.courtlistener.com/opinion/40358/united-states-v-freeman/>. Julgado em 23 de dezembro de 2005. Acesso em: 16 abr. 2019. 2005.

ESTADOS UNIDOS DA AMÉRICA. Corte de Apelação do Nono Circuito Federal. N. do recurso: 03-10585. Apelante: Estados Unidos da América e Carmen Denise Heredia. Disponível em: < http://caselaw.findlaw.com/us-9th-circuit/1043763.html >. Julgado em 02 de abril de 2007. Acesso em: 16 abr. 2019. 2007.

ESTADOS UNIDOS DA AMÉRICA. Corte de Apelação do Sétimo Circuito Federal. N. do recurso: 07-1801, 07-2251 e 07-2596. Apelantes: Estados Unidos da América, Arthia Lamont Tanner Larry Scott e Lance Foster. Disponível em: $<$ http://caselaw.findlaw.com/us-7th-circuit/1411912.html $>$. Julgado em 12 de setembro de 2008. Acesso em: 16 abr. 2019. 2008.

ESTADOS UNIDOS DA AMÉRICA. Corte de Apelação do Terceiro Circuito Federal. N. do recurso: 09-1575. Apelante: Richard Stadtmauer. Disponível em: $<$ http://caselaw.findlaw.com/us-3rd-circuit/1537754.html $>$. Julgado em 09 de setembro de 2010. Acesso em: 16 abr. 2019. 2010.

ESTADOS UNIDOS DA AMÉRICA. Suprema Corte. N. do recurso: 10-6. Recorrente: Global-Tech Appliances, Inc.. Disponível em: $<$ https://supreme.justia.com/cases/federal/us/563/754/>. Julgado em 31 de maio de 2011. Acesso em: 16 abr. 2019. 2011.

ESTADOS UNIDOS DA AMÉRICA. Corte de Apelação do Sexto Circuito Federal. N. do recurso: 94-9478. Apelantes: Estados Unidos da América e Katherine Ann Mitchell. Disponível em: <https://cases.justia.com/federal/appellate-courts/ca6/11-3656/113656-2012-06-13.pdf?ts=1411024917>. Julgado em 13 de junho de 2012. Acesso em: 16 abr. 2019. 2012.

ESTADOS UNIDOS DA AMÉRICA. Corte de Apelação do Quinto Circuito Federal. Quesitação modelo de jurados. Disponível em: $<$ http://www.lb5.uscourts.gov/viewer/?/juryinstructions/Fifth/crim2015.pdf $>$. Acesso em: 25 fev. 2019. 2015. 
ESTADOS UNIDOS DA AMÉRICA. Corte de Apelação do Sétimo Circuito Federal. Quesitação modelo de jurados. Disponível em: $<$ http://www.lb5.uscourts.gov/viewer/?/juryinstructions/Fifth/crim2015.pdf >._Acesso em: 25 fev. 2019. 2016.

FERRAZ, Sérgio Valadão. O valor da cegueira deliberada no sistema de imputação brasileiro: a cegueira deliberada como indicador qualificado do significado do dolo. Tese de doutorado - Fac. de Direito, Universidade Federal do Paraná, 2018. Orientador Prof. Dr. Paulo César Busato. 2018.

FRISCH, Wolfgang. Pena, delito y sistema del delito en transformación. In: InDret, 3, 2014.

FRISCH, Wolfgang; JAKOBS, Gunther; ROXIN, Claus; SCHUNEMANN, Bernd; KOHLER, Michael. Sobre el estado de la teoria del delito. Madrid: Civitas Ediciones, 2000.

GOMES, Enéias Xavier. Dolo sem vontade psicológica: perspectivas de aplicação no Brasil. Belo Horizonte: Editora D’Plácido, 2017.

GRECO, Luís. Introdução à dogmática funcionalista do delito. Revista Brasileira de Ciências Criminais, São Paulo, n. 32, XXX, 2000.

GRECO, Luís. Algumas observações introdutórias à "Distinção entre dolo e culpa", de Ingeborg Puppe. In: A distinção entre dolo e culpa. São Paulo: Manole, 2004.

GRECO, Luís. Um panorama da teoria da imputação objetiva. Rio de Janeiro: Lumen Juris, 2005.

GRECO, Luís. Dolo sem vontade. In: Liber Amicorum de José de Sousa Brito em comemoração do $70^{\circ}$ aniversário. Coimbra: Almedina, 2009.

GRECO, Luís. Comentario ao artículo de Ramón Ragués. Discusiones XIII. Ignorancia deliberada y Derecho Penal, Buenos Aires, v. 13-2, 2013.

HAMDANI, Assaf. Mens rea and the cost of ignorance. Virginia Law Review, v. 93, n. 2, 2007.

HART, Herbert Lionel Adolphus. The ascription of responsability and right. Prooceedings of the Aristotelian Society, New Series, v. 49, 1948-1949.

HASSEMER, Winfried. Los elementos característicos del dolo. In: ADCP. Tradução de María del Mar Días Pira. Madrid: Centro de Publicaciones del Ministerio de Justicia, 1990.

HERRING, Jonathan. Criminal Law. 6. ed. Nova Iorque: Plagrave Macmillan, 2009. 
HERZBERG, Rolf Dietrich. Reflexiones sobre la teoría final de la acción. Revista Electrónica de Ciencia Penal y Criminología, 2008.

HIRSCH, Hans Joachim. Derecho penal. Buenos Aires: Rubinzal Culzoni Editores, 2005.

HRUSCHKA, Joachim. Imputación y derecho penal - estudios sobre la teoría de la imputación. Navarra: Garrigues Cátedra, 2005.

HRUSCHKA, Joachim. Sobre la difícil prueba del dolo. In: Imputación y Estudios de Derecho penal. 2. ed. Buenos Aires: B de F, 2009.

HUSAK, Douglas N.; CALLENDER, Craig A. Willful ignorance, Knowledge, and the 'Equal Culpability' Thesis: a Study of the Deeper Significance of the Principle of Legality. WLR, 1994.

HUSAK, Douglas. The Philosophy of Criminal Law - selected essays. Oxford Scholarship Online, 2010.

JAKOBS, Günther. Sobre la función de la parte subjetiva del delito en Derecho Penal. Anuario de derecho penal y ciencias penales, ISSN 0210-3001, Tomo 42, Fasc/Mes 2, p. 633-652, 1989.

JAKOBS, Günther. El concepto jurídico-penal de acción. In: Estudios de Derecho penal. Madrid: Atelier, 1997-A.

JAKOBS, Günther. Sobre el tratamento de los defectos volitivos y de los defectos cognitivos. In: Estudios de Derecho Penal. Madrid: Atelier, 1997-B.

JAKOBS, Günther. Tratado de derecho penal. Marcial Pons, 1997-C.

JAKOBS, Günther. Sobre la normativización de la dogmática jurídico-penal. Madrid: Civitas, 2003.

JAKOBS, Günther. A imputação objetiva no direito penal. Trad. André Luís Callegari. 5. ed. São Paulo: Revista dos Tribunais, 2014.

JORDAN, David C. Drug Politics. Oklahoma: Norman, 1999.

KAENEL, Fran J. Von. Willful Blindness: a permissive substitute for actual knowledge under the Money laundering control act? Washington University Law Review, v. 71, exemplar 4, 1993.

KAUFMANN, Armin. El dolo eventual en la estructura del delito. Anuario de Derecho Penal y Ciencias Penales. Madrid, v. 2, n. 13, 1960.

LAURENZO COPELLO, Patricia. Dolo y conocimiento. Valencia: Tirant Lo Blanch, 1999. 
LEITE, Alaor. Dúvida e erro sobre a proibição no direito penal. São Paulo: Atlas, 2013.

LUBAN, David. Contrived Ignorance. GLT, 87, 1999.

LUBAN, David. Legal Ethics and Human Dignity, In: Cambridge studies in Philosophy and Law, Cambridge University Press, 2009.

LUCCHESI, Guilherme Brenner. Punindo a culpa como dolo: o uso da cegueira deliberada no Brasil. São Paulo: Marcial Pons, 2018-A.

LUCCHESI, Guilherme Brenner. Acertando por acaso: uma análise da cegueira deliberada como fundamento para a condenação por lavagem de dinheiro no voto da Ministra Rosa Weber na APN 470. Jornal de Ciências Criminais, São Paulo, v. 1, n.1, p. 93-106, jul.dez. 2018-B.

MARCUS, Jonathan L. Model Penal Code section 2.02 (7) and Willful Blindness. The Yale Journal, v. 102, n. 8, Symposium: Economic Competitiveness and the Law, 1993.

MAYER, Max Ernst. Derecho penal: parte general. Buenos Aires: BdeF, 2008.

MELIÁ, Manuel Cancio. ¿Crisis del lado subjetivo del hecho? In: Dogmática y ley penal. Libro homenaje a Enrique Bacigalupo. Madrid-Barcelona: Atelier, 2004. t. I

MELIÁ, Manuel Cancio; JAKOBS, Gunther. Direito penal do inimigo - Noções e críticas. Porto Alegre: Livraria do Advogado, 2009.

MEZGER, Edmund. Tratado de derecho penal. Madrid: Revista de Derecho, 1957.

MIR PUIG, Santiago. Límites del normativismo en derecho penal. Revista electrónica de ciencia penal y criminología, ISSN-e 1695-0194, n. 7, 2005.

MORO, Sergio Fernando. Crime de lavagem de dinheiro. São Paulo: Saraiva, 2010.

NAYLOR, Robin Thomas. Wages of Crime - Black Markets, Illegal Finance and the Underworld Economy. Ithaca and London: Cornell University Press, 2002.

OXMAN, Nicolás. Una aproximación al sistema de imputación subjectiva en el derecho penal aglosaxón. Revista Ius et Praxis, Santiago, ano 19, n. 1, 2013.

PÉREZ BARBERÁ, Gabriel. El dolo eventual. Buenos Aires: Editorial Hammurabi, 2011.

PÉREZ BARBERÁ, Gabriel. Dolo como reproche. Hacia el abandono de la idea de dolo como estado mental. In: Pensar en derecho, 1, 2012.

PERKINS, M.; BOYCE, Ronald N. Criminal Law. Foundation Press 3. d., 1982.

PLANAS, Ricardo Robles. Estudos de dogmática jurídico-penal: Fundamentos, teoria do delito e direito penal econômico. Belo Horizonte: D’Plácido, 2016. 
PORCIUNCULA, José Carlos. Lo objetivo y lo subjetivo en el tipo penal: hacia la exteriorización de lo interno. Barcelona: Atelier Libros Jurídicos, 2014.

PORTUGAL. Código Penal, Decreto Lei n. 48/1995. Disponível em: $<$ http://www.pgdlisboa.pt/leis/lei_mostra_articulado.php?nid=109\&tabela=lei_velhas \&nversao=1\&so_miolo=>. Acesso em: 16 abr. 2019. 1995.

PUPPE, Ingeborg. Dolo eventual e culpa consciente. Revista Brasileira de Ciências Criminais, São Paulo, v. 14, n. 58. 2006.

PUPPE, Ingeborg. La construcción del delito. Trad.: Diego Leif Guardia. Revista de Derecho Penal, n. 2, 2007.

PUPPE, Ingeborg. La distinción entre dolo y culpa. Tradução, introdução e notas: Luis Greco. São Paulo: Manole, 2009.

PUPPE, Ingeborg. Dolo y desviación causal. Revista de derecho penal y procesal penal, Abeledo Perrot, n. 9, 2010.

PUPPE, Ingeborg. Estudos sobre imputação objetiva e subjetiva no direito penal. Organização: Beatriz Corrêa Camargo e Wagner Martelo Filho; Tradução: Luís Greco, Beatriz Corrêa Camargo, Wagner Martelo Filho e Luiz Henrique Carvalheiro Rossetto. - 1. Ed.: São Paulo, 2019.

QUINTON, Anthony. Knowledge and belief. Ed.: Paul Edwards, 1967.

RAGUÉS I VALLÈS, Ramón. La Atribución del conocimiento en el ámbito de la imputación dolosa. Universitat Pompeu Fabra, 1998.

RAGUÉS I VALLÈS, Ramón. El dolo y su prueba en el processo penal. Barcelona: J. M. Bosch Editor, 1999-A.

RAGUÉS I VALLĖS, Ramón. Tres propuestas recientes en la histórica discusión sobre el dolo. Cuadernos de doctrina y jurisprudencia penal, Buenos Aires: Ad-Hoc, año V, n. 09, p. 465 e ss., 1999-B.

RAGUÉS I VALLÈS, Ramón. La ignorancia deliberada en derecho penal. [s.1.]: Atelier, 2007.

RAGUÉS I VALLÈS, Ramón. De nuevo, el dolo eventual: un enfoque revolucionario para un tema clásico, In: InDret, 2012.

RAGUÉS I VALLÈS, Ramón. Mejor no saber: sobre la doctrina de la ignorancia deliberada en derecho penal, In: InDret, 2013.

ROBBINS, Ira. The Ostrich Instruction: Deliberate Ignorance as a Criminal Mens Rea; 81 Journal of Criminal Law and Criminology, 191, 1990. 
ROBINSON, Paul H. A brief history of Distinctions in Criminal Culpability. The Hasting Journal, v. 31, n. 4, 1980.

ROXIN, Claus. Teoría del tipo penal: tipos abiertos y elementos del deber jurídico. Madrid: Depalma, 1979.

ROXIN, Claus. Contribuição para a crítica da teoria finalista da acção. Problemas fundamentais de direito penal. Trad. Ana Paula dos Santos Luís Natscheradetz. Lisboa: Vega, 1993.

ROXIN, Claus. Derecho penal - Parte general. Fundamentos. La estructura de la teoria del delito. Madrid: Civitas, 1997. t. I.

ROXIN, Claus. La evolución de la política criminal, el derecho penal y el proceso penal. Valencia: Depalma, 2000.

ROXIN, Claus. La teoría del delito en la discusión actual. Lima: Cartoné, 2007.

ROXIN, Claus. Estudos de direito penal. Rio de Janeiro: Renovar, 2008-A.

ROXIN, Claus. Derecho penal: parte general. Trad. Diego Manuel Luzón Peña, Miguel Días y García Conlledo y Javier Vicente Remesal. Madrid: Civitas, 2008-B.

SALVADOR NETTO, Alamiro Velludo. Tipicidade penal e sociedade de risco. São Paulo: Quartier Latin, 2006.

SÁNCHEZ, Bernardo Feijoo. La teoría de la ignorancia deliberada en derecho penal: una peligrosa doctrina jurisprudencial. In: InDret, 3, 2015.

SARCH, Alexander F. Willful Ignorance, Culpability, and the Criminal Law, 2014

SCHMIDT, Andrei Zenkner. Direito penal econômico: parte geral. Porto Alegre: Livraria do Advogado, 2015.

SHECAIRA, Sérgio Salomão. Dolo eventual e culpa consciente. Revista Brasileira de Ciências Criminais, v. 38, 2002.

SHECAIRA, Sérgio Salomão. Ainda a expansão do direito penal: o papel do dolo eventual. Revista Brasileira de Ciências Criminais, São Paulo, v. 64, 2007.

SILVA SÁNCHEZ, Jesús-María. Aproximação ao direito penal contemporâneo. Trad. Roberto Barbosa Alves. São Paulo: Revista dos Tribunais, 2011.

SILVA SÁNCHEZ, Jesús-María. A expansão do direito penal: aspectos da política criminal nas sociedades pós-industriais. 3. ed. rev. e atual. São Paulo: Revista dos Tribunais, 2013. 
SILVEIRA, Renato de Mello Jorge. A teoria do delito e o enigma do dolo eventual: considerações sobre a aparente nova resposta italiana. Revista Brasileira de Ciências Criminais, v. 121, 2016-A.

SILVEIRA, Renato de Mello Jorge. A aplicação da Teoria da Cegueira Deliberada nos julgamentos da operação lava jato. Revista Brasileira de Ciências Criminais, v. 122, 2016-B.

SILVEIRA, Renato de Mello Jorge. Anotações sobre o estudo da recklessness na doutrina penal italiana: por uma terceira forma de imputação subjetiva? Revista Brasileira de Ciências Criminais, v. 137, 2017.

SMITH, Holly. Culpable Ignorance. The philosophical review, XCII, n. 4, out. 1983.

SOL, Inés Sandro. La ignorancia deliberada del derecho penal: dolo o culpa? Las Tesinas de Belgrano, Buenos Aires: Universidad de Belgrano, n. 505, 2012.

STRANGE, Susan. The retreat of the State - The diffusion of Power in the World Economy. Cambridge: Cambridge University Press, 1996.

SYDOW, Spencer Toth. A teoria da cegueira deliberada. Belo Horizonte: Editora D’Plácido, 2017.

TARUFFO, Michele. La prueba de los hechos. Trad. Jordi Ferrer Beltrán. Madrid: Editorial Trotta, 2002.

TARUFFO, Michele. La Prueba. Artículos y Conferencias. Santiago. Editorial: Metropolitana, 2009.

TAVARES, Juarez. Espécies de dolo e outros elementos subjetivos do tipo. Revista de Direito Penal, São Paulo, v. 6, 1972.

TAVARES, Juarez. Direito penal da negligência. São Paulo: Revista dos Tribunais, 1985.

TAVARES, Juarez. Teoria do injusto penal. 3. ed. Belo Horizonte: Del Rey, 2003.

TAVARES, Juarez. Teoria dos crimes omissivos. São Paulo: Marcial Pons, 2012.

TIGRE MAIA, Rodolfo. Lavagem de dinheiro - Lavagem de ativos provenientes de crime e anotações às disposições criminais da Lei n. 9.613/98. São Paulo: Malheiros, 1999.

VALENZUELA S., Jonatan. Ignorancia deliberada y Derecho Penal. Revista Discusiones, Buenos Aires, n. XIII, 2015.

VIANA, Eduardo. Dolo como compromisso cognitivo. São Paulo: Marcial Pons, 2017. 
VIVES ANTÓN, Tomás Salvador. Reexame do dolo. In: BUSATO, Paulo César (org.). Dolo e direito penal: modernas tendências. 2. ed. São Paulo: Atlas, 2014.

WALSH, Brian W. The Supreme Court's Willful Blindness Doctrine Opens the Door to More Wrongful Criminal Convictions. The Heritage Foundation, n. 3304, June 2011.

WESCHLER, Herbert. On culpability and crime: the treatment of mens rea in the Model Penal Code. The Annals of the American Academy of Political and Social Science, v. 339, 1962.

WILLIAMS, Glanville. Criminal law: the general part. 2. ed., Londres: Stevens \& Sons, 1961.

WILLIAMS, Glanville. Textbook of criminal law. 2. ed., Londres: Stevens \& Sons, 1983.

ZAFFARONI, Eugenio Raúl; PIERANGELI, José Henrique. Manual de direito penal brasileiro. 9. ed. rev. e atual. São Paulo: Revista dos Tribunais, 2011.

ZIMMERMAN, Michael J. Moral responsability and ignorance. Ethics, v. 107, n. 3 p. 410426, abr. 1997. 


\section{ANEXO - ACÓRDÃOS DO TRIBUNAL REGIONAL FEDERAL DA $4^{\text {a }}$ REGIÃO COM MENÇÃO À CEGUEIRA DELIBERADA}

\begin{tabular}{|c|c|c|}
\hline Classe & Número do processo & Classificação \\
\hline Apelação & $2003.70 .00 .056661-8$ & Terceiro grupo \\
\hline Apelação & 0002106-90.2009.4.04.7009 & Terceiro grupo \\
\hline Apelação & $5000247-83.2011 .4 .04 .7008$ & Terceiro grupo \\
\hline Apelação & $0000870-49.2008 .4 .04 .7006$ & Terceiro grupo \\
\hline Apelação & $5004121-31.2010 .4 .04 .7002$ & Terceiro grupo \\
\hline Apelação & 5002764-27.2012.4.04.7202 & Terceiro grupo \\
\hline Apelação & $5007098-25.2012 .4 .04 .7002$ & Terceiro grupo \\
\hline Apelação & $0002468-55.2005 .4 .04 .7002$ & Terceiro grupo \\
\hline Apelação & 5009426-59.2011.4.04.7002 & Terceiro grupo \\
\hline Apelação & $5009722-81.2011 .404 .7002$ & Primeiro grupo \\
\hline Apelação & $0010198-89.2006 .4 .04 .7000$ & Terceiro grupo \\
\hline Apelação & $5001450-29.2010 .4 .04 .7004$ & Primeiro grupo \\
\hline Apelação & 5001079-31.2011.404.7004 & Primeiro grupo \\
\hline Apelação & $5002349-12.2010 .404 .7009$ & Terceiro grupo \\
\hline Apelação & $5003936-90.2010 .404 .7002$ & Primeiro grupo \\
\hline Apelação & $5000220-41.2013 .404 .7005$ & Primeiro grupo \\
\hline Apelação & $5003108-54.2011 .404 .7004$ & Primeiro grupo \\
\hline Apelação & $5007232-52.2012 .404 .7002$ & Primeiro grupo \\
\hline Apelação & $5005343-42.2012 .404 .7009$ & Terceiro grupo \\
\hline Apelação & $5004921-54.2013 .404 .7002$ & Primeiro grupo \\
\hline Apelação & $5000742-48.2011 .404 .7002$ & Primeiro grupo \\
\hline Apelação & 5000936-76.2010.404.7004 & Primeiro grupo \\
\hline Apelação & $5008967-57.2011 .404 .7002$ & Primeiro grupo \\
\hline Apelação & $5005012-47.2013 .404 .7002$ & Terceiro grupo \\
\hline $\begin{array}{c}\text { Recurso em } \\
\text { sentido estrito }\end{array}$ & $5007072-90.2013 .404 .7002$ & Primeiro grupo \\
\hline Apelação & 5005316-46.2013.404.7002 & Terceiro grupo \\
\hline Apelação & $5000295-12.2011 .404 .7115$ & Primeiro grupo \\
\hline Apelação & $5005740-88.2013 .404 .7002$ & Terceiro grupo \\
\hline Apelação & $5000007-96.2013 .404 .7017$ & Terceiro grupo \\
\hline Apelação & $5000571-28.2010 .404 .7002$ & Terceiro grupo \\
\hline Apelação & 5000059-24.2010.404.7009 & Primeiro grupo \\
\hline Apelação & $5041461-10.2013 .404 .7000$ & Terceiro grupo \\
\hline Apelação & $5011000-83.2012 .404 .7002$ & Primeiro grupo \\
\hline
\end{tabular}




\begin{tabular}{|c|c|c|}
\hline Classe & Número do processo & Classificação \\
\hline Apelação & 0000625-16.2009.404.7002 & Terceiro grupo \\
\hline Apelação & 0009867-38.2005.404.7002 & Terceiro grupo \\
\hline Apelação & 5001636-11.2013.404.7016 & Terceiro grupo \\
\hline Apelação & $5002540-78.2010 .404 .7002$ & Terceiro grupo \\
\hline Apelação & $5001640-52.2011 .404 .7102$ & Terceiro grupo \\
\hline Apelação & $5006909-47.2012 .404 .7002$ & Terceiro grupo \\
\hline Apelação & $5001493-77.2012 .404 .7203$ & Terceiro grupo \\
\hline Apelação & $0005008-45.2006 .404 .7001$ & Primeiro grupo \\
\hline Apelação & $5001685-75.2010 .404 .7204$ & Terceiro grupo \\
\hline Apelação & $5000114-09.2014 .404 .7017$ & Terceiro grupo \\
\hline Apelação & $0000710-55.2007 .404 .7201$ & Terceiro grupo \\
\hline Apelação & $5001920-87.2011 .404 .7016$ & Terceiro grupo \\
\hline Apelação & 5003196-35.2010.404.7002 & Terceiro grupo \\
\hline Apelação & $5000053-72.2009 .404 .7002$ & Terceiro grupo \\
\hline Apelação & 5004606-31.2010.404.7002 & Primeiro grupo \\
\hline Apelação & $0000997-62.2009 .404 .7002$ & Terceiro grupo \\
\hline Apelação & $5003037-58.2011 .404 .7002$ & Terceiro grupo \\
\hline $\begin{array}{l}\text { Habeas } \\
\text { Corpus }\end{array}$ & $5012436-63.2014 .404 .0000$ & Terceiro grupo \\
\hline Apelação & $5011699-80.2012 .404 .7000$ & Terceiro grupo \\
\hline Apelação & $5003863-84.2011 .404 .7002$ & Primeiro grupo \\
\hline Apelação & 5000124-35.2013.404.7002 & Primeiro grupo \\
\hline Apelação & 0000091-85.2008.404.7106 & Primeiro grupo \\
\hline Apelação & 5011294-04.2013.404.7002 & Terceiro grupo \\
\hline Apelação & 5006197-23.2013.404.7002 & Primeiro grupo \\
\hline Apelação & 0005403-89.2001.404.7105 & Primeiro grupo \\
\hline Apelação & $5003712-77.2014 .404 .7208$ & Terceiro grupo \\
\hline Apelação & $5003712-77.2014 .404 .7208$ & Terceiro grupo \\
\hline Apelação & $5000552-17.2013 .404 .7002$ & Primeiro grupo \\
\hline $\begin{array}{c}\text { Recurso em } \\
\text { sentido estrito }\end{array}$ & 5005418-34.2014.404.7002 & Primeiro grupo \\
\hline Apelação & $5002100-77.2013 .404 .7002$ & Primeiro grupo \\
\hline $\begin{array}{l}\text { Habeas } \\
\text { Corpus }\end{array}$ & 5026974-49.2014.404.0000 & Terceiro grupo \\
\hline Apelação & 5001384-07.2014.404.7005 & Primeiro grupo \\
\hline Apelação & $5002812-72.2010 .404 .7002$ & Primeiro grupo \\
\hline Apelação & $5002824-35.2014 .404 .7006$ & Terceiro grupo \\
\hline Apelação & 5006891-17.2012.404.7005 & Primeiro grupo \\
\hline
\end{tabular}




\begin{tabular}{|c|c|c|}
\hline Classe & Número do processo & Classificação \\
\hline $\begin{array}{c}\text { Recurso em } \\
\text { sentido estrito }\end{array}$ & $5009783-34.2014 .404 .7002$ & Primeiro grupo \\
\hline Apelação & $5010757-42.2012 .404 .7002$ & Primeiro grupo \\
\hline Apelação & $5001640-11.2014 .404 .7017$ & Terceiro grupo \\
\hline Apelação & $5004058-57.2011 .404 .7006$ & Primeiro grupo \\
\hline Apelação & $5062328-15.2013 .404 .7100$ & Primeiro grupo \\
\hline Apelação & $0000974-45.2007 .404 .7016$ & Terceiro grupo \\
\hline Apelação & 0002803-60.2008.404.7005 & Terceiro grupo \\
\hline Apelação & 5001945-68.2013.404.7004 & Primeiro grupo \\
\hline Apelação & $5062328-15.2013 .404 .7100$ & Primeiro grupo \\
\hline Apelação & $5005108-62.2013 .404 .7002$ & Terceiro grupo \\
\hline Apelação & $5005185-34.2014 .404 .7003$ & Primeiro grupo \\
\hline Apelação & $5005123-23.2012 .404 .7113$ & Primeiro grupo \\
\hline Apelação & $5055075-44.2011 .404 .7100$ & Terceiro grupo \\
\hline Apelação & 5002013-92.2011.404.7002 & Terceiro grupo \\
\hline Apelação & 5000095-34.2013.404.7115 & Primeiro grupo \\
\hline Apelação & $5000462-83.2012 .404 .7118$ & Primeiro grupo \\
\hline Apelação & $5004477-06.2013 .404 .7007$ & Primeiro grupo \\
\hline Apelação & $5011122-62.2013 .404 .7002$ & Primeiro grupo \\
\hline Apelação & $5004064-08.2013 .404 .7002$ & Primeiro grupo \\
\hline Apelação & 5004064-08.2013.404.7002 & Primeiro grupo \\
\hline Apelação & $5003041-61.2012 .404 .7002$ & Terceiro grupo \\
\hline Apelação & $5005792-69.2013 .404 .7104$ & Terceiro grupo \\
\hline Apelação & $5011017-51.2014 .404 .7002$ & Terceiro grupo \\
\hline Apelação & $5001428-87.2014 .404 .7017$ & Terceiro grupo \\
\hline Apelação & $5001669-88.2010 .404 .7118 /$ & Primeiro grupo \\
\hline Apelação & $5008320-91.2013 .404 .7002$ & Primeiro grupo \\
\hline Apelação & 5010349-80.2014.404.7002 & Terceiro grupo \\
\hline Apelação & $5011412-14.2012 .404 .7002$ & Terceiro grupo \\
\hline Apelação & $5049734-41.2014 .404 .7000$ & Terceiro grupo \\
\hline Apelação & $5003420-18.2011 .404 .7202$ & Terceiro grupo \\
\hline Apelação & $5003040-42.2013 .404 .7002$ & Terceiro grupo \\
\hline Apelação & $5000137-78.2011 .404 .7010$ & Primeiro grupo \\
\hline Apelação & 5009665-29.2012.4.04.7002 & Terceiro grupo \\
\hline Apelação & $5014585-46.2012 .4 .04 .7002$ & Primeiro grupo \\
\hline Apelação & 5004125-63.2013.4.04.7002 & Primeiro grupo \\
\hline Apelação & $5003776-79.2012 .4 .04 .7007$ & Primeiro grupo \\
\hline Apelação & $5006848-76.2014 .4 .04 .7210$ & Terceiro grupo \\
\hline
\end{tabular}




\begin{tabular}{|c|c|c|}
\hline Classe & Número do processo & Classificação \\
\hline Apelação & 5009366-18.2013.4.04.7002 & Primeiro grupo \\
\hline Apelação & 5010419-05.2011.4.04.7002 & Primeiro grupo \\
\hline Apelação & $5002757-32.2012 .4 .04 .7106$ & Terceiro grupo \\
\hline Apelação & 5019147-41.2011.4.04.7000 & Primeiro grupo \\
\hline Apelação & $5000437-56.2010 .4 .04 .7016$ & Terceiro grupo \\
\hline Apelação & 5000304-96.2010.4.04.7118 & Terceiro grupo \\
\hline Apelação & 5000304-96.2010.4.04.7118 & Terceiro grupo \\
\hline Apelação & 5003762-32.2011.4.04.7007 & Terceiro grupo \\
\hline Apelação & $5001461-30.2011 .4 .04 .7002$ & Terceiro grupo \\
\hline Apelação & $5002361-47.2010 .4 .04 .7002$ & Terceiro grupo \\
\hline Apelação & 5002443-10.2012.4.04.7002 & Terceiro grupo \\
\hline Apelação & 5005396-78.2011.4.04.7002 & Terceiro grupo \\
\hline Apelação & $5000764-58.2015 .4 .04 .7005$ & Terceiro grupo \\
\hline Apelação & 0002476-27.2008.4.04.7002 & Primeiro grupo \\
\hline Apelação & $5006743-13.2011 .4 .04 .7208$ & Primeiro grupo \\
\hline Apelação & 0004489-07.2006.4.04.7216 & Terceiro grupo \\
\hline Apelação & 5003693-49.2010.4.04.7002 & Primeiro grupo \\
\hline Apelação & $5004961-46.2012 .4 .04 .7010$ & Primeiro grupo \\
\hline Apelação & 5001410-68.2011.4.04.7212 & Primeiro grupo \\
\hline Apelação & $5012112-87.2012 .4 .04 .7002$ & Terceiro grupo \\
\hline Apelação & 5003516-07.2014.4.04.7015 & Terceiro grupo \\
\hline Apelação & 5007195-25.2012.4.04.7002 & Terceiro grupo \\
\hline Apelação & $5002923-22.2011 .4 .04 .7002$ & Terceiro grupo \\
\hline Apelação & 5002751-80.2011.4.04.7002 & Primeiro grupo \\
\hline Apelação & $5006854-62.2013 .4 .04 .7002$ & Primeiro grupo \\
\hline Apelação & 5004440-62.2011.4.04.7002 & Terceiro grupo \\
\hline Apelação & 5009790-51.2013.4.04.7102 & Primeiro grupo \\
\hline Apelação & $5000577-95.2011 .4 .04 .7003$ & Primeiro grupo \\
\hline Apelação & $5001699-88.2012 .4 .04 .7010$ & Terceiro grupo \\
\hline Apelação & $0023769-50.2008 .4 .04 .7100$ & Primeiro grupo \\
\hline Apelação & $0000547-47.2008 .4 .04 .7102$ & Terceiro grupo \\
\hline Apelação & $5000076-42.2014 .4 .04 .7002$ & Terceiro grupo \\
\hline Apelação & $5004210-83.2012 .4 .04 .7002$ & Terceiro grupo \\
\hline Apelação & $5006501-89.2013 .4 .04 .7206$ & Primeiro grupo \\
\hline Apelação & $5055357-57.2012 .4 .04 .7000$ & Terceiro grupo \\
\hline Apelação & $5012262-68.2012 .4 .04 .7002$ & Terceiro grupo \\
\hline Apelação & $5015653-60.2014 .4 .04 .7002$ & Terceiro grupo \\
\hline
\end{tabular}




\begin{tabular}{|c|c|c|}
\hline Classe & Número do processo & Classificação \\
\hline $\begin{array}{l}\text { Habeas } \\
\text { Corpus }\end{array}$ & 5037929-08.2015.4.04.0000 & Terceiro grupo \\
\hline Apelação & $5000043-33.2011 .4 .04 .7010$ & Primeiro grupo \\
\hline Apelação & $5001231-40.2015 .4 .04 .7004$ & Primeiro grupo \\
\hline Apelação & 5001684-12.2013.4.04.7002 & Primeiro grupo \\
\hline Apelação & $5008479-45.2010 .4 .04 .7000$ & Primeiro grupo \\
\hline Apelação & $5014525-84.2014 .4 .04 .7202$ & Primeiro grupo \\
\hline Apelação & $5000406-39.2014 .4 .04 .7002$ & Terceiro grupo \\
\hline Apelação & 5002179-27.2011.4.04.7002 & Terceiro grupo \\
\hline Apelação & $0001041-67.2008 .4 .04 .7115$ & Primeiro grupo \\
\hline Apelação & 5001611-39.2010.4.04.7004 & Primeiro grupo \\
\hline Apelação & 5003881-71.2012.4.04.7002 & Primeiro grupo \\
\hline Apelação & $5006992-54.2012 .4 .04 .7005$ & Terceiro grupo \\
\hline Apelação & $5004342-17.2015 .4 .04 .7009$ & Terceiro grupo \\
\hline Apelação & 5006880-17.2014.4.04.7005 & Terceiro grupo \\
\hline Apelação & $5009435-69.2012 .4 .04 .7104$ & Terceiro grupo \\
\hline Apelação & 5002013-92.2011.4.04.7002 & Terceiro grupo \\
\hline Apelação & $5006618-72.2011 .4 .04 .7005$ & Terceiro grupo \\
\hline Apelação & $5006618-72.2011 .4 .04 .7005$ & Primeiro grupo \\
\hline Apelação & $5002350-16.2014 .4 .04 .7119$ & Primeiro grupo \\
\hline Apelação & $5007445-92.2011 .4 .04 .7002$ & Primeiro grupo \\
\hline Apelação & $5011242-73.2011 .4 .04 .7100$ & Primeiro grupo \\
\hline Apelação & 5003823-39.2010.4.04.7002 & Terceiro grupo \\
\hline Apelação & $5068592-14.2014 .4 .04 .7100$ & Terceiro grupo \\
\hline Apelação & $5012479-43.2014 .4 .04 .7002$ & Primeiro grupo \\
\hline Apelação & $5014377-91.2014 .4 .04 .7002$ & Primeiro grupo \\
\hline Apelação & $5000842-85.2011 .4 .04 .7007$ & Primeiro grupo \\
\hline Apelação & $5001062-30.2013 .4 .04 .7002$ & Primeiro grupo \\
\hline Apelação & $5012726-21.2014 .4 .04 .7003$ & Terceiro grupo \\
\hline Apelação & $5010415-30.2014 .4 .04 .7206$ & Terceiro grupo \\
\hline Apelação & 5004059-30.2011.4.04.7010 & Primeiro grupo \\
\hline Apelação & $5000664-19.2014 .4 .04 .7012$ & Terceiro grupo \\
\hline Apelação & $5003501-73.2011 .4 .04 .7005$ & Terceiro grupo \\
\hline Apelação & 0010790-86.2004.4.04.7200 & Primeiro grupo \\
\hline Apelação & $5004813-19.2013 .4 .04 .7004$ & Terceiro grupo \\
\hline Apelação & $5084080-09.2014 .4 .04 .7100$ & Primeiro grupo \\
\hline Apelação & $5084080-09.2014 .4 .04 .7100$ & Primeiro grupo \\
\hline
\end{tabular}




\begin{tabular}{|c|c|c|}
\hline Classe & Número do processo & Classificação \\
\hline $\begin{array}{c}\text { Recurso em } \\
\text { sentido estrito }\end{array}$ & $5000478-55.2016 .4 .04 .7002$ & Terceiro grupo \\
\hline Apelação & 5004837-19.2014.4.04.7002 & Primeiro grupo \\
\hline Apelação & 5005844-80.2013.4.04.7002 & Primeiro grupo \\
\hline Apelação & 5003185-15.2015.4.04.7007 & Primeiro grupo \\
\hline Apelação & $5000405-42.2014 .4 .04 .7006$ & Primeiro grupo \\
\hline Apelação & $5001907-17.2013 .4 .04 .7017$ & Primeiro grupo \\
\hline Apelação & 5006175-91.2015.4.04.7002 & Terceiro grupo \\
\hline Apelação & $5006015-37.2013 .4 .04 .7002$ & Primeiro grupo \\
\hline Apelação & $5000562-81.2015 .4 .04 .7005$ & Primeiro grupo \\
\hline Apelação & 5000256-87.2016.4.04.7002 & Primeiro grupo \\
\hline Apelação & $5057359-88.2012 .4 .04 .7100$ & Primeiro grupo \\
\hline Apelação & $5000344-96.2014 .4 .04 .7002$ & Primeiro grupo \\
\hline Apelação & $5002983-32.2015 .4 .04 .7203$ & Terceiro grupo \\
\hline Apelação & 5006150-78.2015.4.04.7002 & Primeiro grupo \\
\hline Apelação & $5004030-81.2014 .4 .04 .7007$ & Primeiro grupo \\
\hline Apelação & $5000629-10.2015 .4 .04 .7017$ & Terceiro grupo \\
\hline Apelação & 5002790-79.2013.4.04.7011 & Terceiro grupo \\
\hline Apelação & $5014182-91.2014 .4 .04 .7201$ & Terceiro grupo \\
\hline Apelação & $5001956-26.2015 .4 .04 .7005$ & Terceiro grupo \\
\hline Apelação & $5015925-54.2014 .4 .04 .7002$ & Terceiro grupo \\
\hline Apelação & 5000746-22.2015.4.04.7010 & Terceiro grupo \\
\hline Apelação & $5001858-21.2013 .4 .04 .7002$ & Terceiro grupo \\
\hline Apelação & 5003654-07.2014.4.04.7101 & Terceiro grupo \\
\hline Apelação & 5006487-58.2015.4.04.7005 & Primeiro grupo \\
\hline Apelação & 5010130-14.2012.4.04.7107 & Terceiro grupo \\
\hline Apelação & $5006921-81.2014 .4 .04 .7005$ & Terceiro grupo \\
\hline Apelação & $5000152-26.2015 .4 .04 .7004$ & Primeiro grupo \\
\hline Apelação & 5013518-14.2015.4.04.7108 & Primeiro grupo \\
\hline Apelação & $5015371-22.2014 .4 .04 .7002$ & Primeiro grupo \\
\hline Apelação & 5000129-75.2014.4.04.7017 & Terceiro grupo \\
\hline Apelação & $5000942-46.2011 .4 .04 .7005$ & Terceiro grupo \\
\hline Apelação & $5008227-31.2013 .4 .04 .7002$ & Primeiro grupo \\
\hline Apelação & $5008227-31.2013 .4 .04 .7002$ & Primeiro grupo \\
\hline Apelação & $5004534-62.2015 .4 .04 .7004$ & Terceiro grupo \\
\hline Apelação & $0003545-56.2006 .4 .04 .7102$ & Terceiro grupo \\
\hline Apelação & $5010929-47.2013 .4 .04 .7002$ & Terceiro grupo \\
\hline Apelação & $5000067-17.2013 .4 .04 .7002$ & Terceiro grupo \\
\hline
\end{tabular}




\begin{tabular}{|c|c|c|}
\hline Classe & Número do processo & Classificação \\
\hline Apelação & $5002372-47.2013 .4 .04 .7010$ & Primeiro grupo \\
\hline Apelação & 5012436-72.2015.4.04.7002 & Terceiro grupo \\
\hline Apelação & $5005343-57.2012 .4 .04 .7101$ & Primeiro grupo \\
\hline Apelação & 5005891-05.2014.4.04.7007 & Terceiro grupo \\
\hline Apelação & 5000887-05.2015.4.04.7119 & Primeiro grupo \\
\hline Apelação & $5009476-46.2015 .4 .04 .7002$ & Terceiro grupo \\
\hline Apelação & 5047229-77.2014.4.04.7000 & Primeiro grupo \\
\hline Apelação & 5009282-46.2015.4.04.7002 & Primeiro grupo \\
\hline Apelação & 5000555-58.2016.4.04.7101 & Terceiro grupo \\
\hline Apelação & 5002963-24.2013.4.04.7005 & Terceiro grupo \\
\hline Apelação & $5003520-79.2011 .4 .04 .7005$ & Primeiro grupo \\
\hline Apelação & $5026212-82.2014 .4 .04 .7000$ & Primeiro grupo \\
\hline Apelação & $5083376-05.2014 .4 .04 .7000$ & Primeiro grupo \\
\hline Apelação & 5001801-03.2013.4.04.7002 & Primeiro grupo \\
\hline Apelação & 5002138-26.2012.4.04.7002 & Primeiro grupo \\
\hline Apelação & 5002570-11.2013.4.04.7002 & Primeiro grupo \\
\hline Apelação & $5001547-40.2012 .4 .04 .7010$ & Terceiro grupo \\
\hline Apelação & 5010934-69.2013.4.04.7002 & Terceiro grupo \\
\hline Apelação & 5009367-66.2014.4.04.7002 & Terceiro grupo \\
\hline Apelação & $5011807-35.2014 .4 .04 .7002$ & Terceiro grupo \\
\hline Apelação & 5002835-42.2015.4.04.7002 & Terceiro grupo \\
\hline Apelação & 0001240-31.2008.4.04.7005 & Terceiro grupo \\
\hline Apelação & $5000908-63.2010 .4 .04 .7116$ & Terceiro grupo \\
\hline Apelação & $5009167-50.2014 .4 .04 .7005$ & Terceiro grupo \\
\hline Apelação & $5027795-59.2015 .4 .04 .7100$ & Primeiro grupo \\
\hline Apelação & 5011825-56.2014.4.04.7002 & Terceiro grupo \\
\hline Apelação & $5007404-57.2013 .4 .04 .7002$ & Terceiro grupo \\
\hline $\begin{array}{l}\text { Habeas } \\
\text { Corpus }\end{array}$ & $5000594-81.2017 .4 .04 .0000$ & Terceiro grupo \\
\hline Apelação & $5002607-25.2015 .4 .04 .7016$ & Terceiro grupo \\
\hline Apelação & $5002027-60.2013 .4 .04 .7017$ & Terceiro grupo \\
\hline Apelação & $5003501-73.2011 .4 .04 .7005$ & Terceiro grupo \\
\hline Apelação & 5035939-36.2012.4.04.7000 & Terceiro grupo \\
\hline Apelação & 5066195-88.2014.4.04.7000 & Terceiro grupo \\
\hline Apelação & 0002055-79.2009.4.04.7009 & Terceiro grupo \\
\hline Apelação & $5003456-02.2012 .4 .04 .7210$ & Terceiro grupo \\
\hline Apelação & 5001071-73.2015.4.04.7017 & Terceiro grupo \\
\hline Apelação & $5003865-16.2014 .4 .04 .7013$ & Terceiro grupo \\
\hline
\end{tabular}




\begin{tabular}{|c|c|c|}
\hline Classe & Número do processo & Classificação \\
\hline Apelação & $5001443-33.2016 .4 .04 .7002$ & Terceiro grupo \\
\hline Apelação & $5003246-56.2013 .4 .04 .7002$ & Primeiro grupo \\
\hline Apelação & $5004108-14.2015 .4 .04 .7210$ & Terceiro grupo \\
\hline Apelação & 5012305-34.2014.4.04.7002 & Terceiro grupo \\
\hline Apelação & $5000028-30.2012 .4 .04 .7010$ & Primeiro grupo \\
\hline Apelação & $5052700-02.2013 .4 .04 .7100$ & Terceiro grupo \\
\hline Apelação & 5006335-10.2015.4.04.7005 & Terceiro grupo \\
\hline Apelação & 5006562-97.2015.4.04.7005 & Primeiro grupo \\
\hline Apelação & $5007535-57.2012 .4 .04 .7005$ & Terceiro grupo \\
\hline Apelação & $5000292-21.2015 .4 .04 .7114$ & Terceiro grupo \\
\hline Apelação & 5005763-91.2014.4.04.7004 & Terceiro grupo \\
\hline Apelação & $5013655-57.2014 .4 .04 .7002$ & Terceiro grupo \\
\hline Apelação & 5008031-30.2014.4.04.7001 & Primeiro grupo \\
\hline Apelação & 5083258-29.2014.4.04.7000 & Primeiro grupo \\
\hline Apelação & $5005944-64.2015 .4 .04 .7002$ & Primeiro grupo \\
\hline Apelação & 5005326-14.2014.4.04.7016 & Terceiro grupo \\
\hline Apelação & $5005188-85.2011 .4 .04 .7005$ & Terceiro grupo \\
\hline Apelação & 5000392-80.2013.4.04.7005 & Terceiro grupo \\
\hline Apelação & $5000388-41.2012 .4 .04 .7114$ & Primeiro grupo \\
\hline Apelação & 5004526-91.2015.4.04.7002 & Terceiro grupo \\
\hline Apelação & 5002482-02.2015.4.04.7002 & Terceiro grupo \\
\hline Apelação & $5002556-53.2011 .4 .04 .7016$ & Primeiro grupo \\
\hline Apelação & $5006444-33.2015 .4 .04 .7002$ & Terceiro grupo \\
\hline Apelação & $5002482-02.2015 .4 .04 .7002$ & Terceiro grupo \\
\hline Apelação & 5002303-62.2015.4.04.7004 & Primeiro grupo \\
\hline Apelação & $5008622-52.2015 .4 .04 .7002$ & Primeiro grupo \\
\hline Apelação & $5004705-79.2016 .4 .04 .7005$ & Primeiro grupo \\
\hline Apelação & $5000709-88.2016 .4 .04 .7000$ & Terceiro grupo \\
\hline Apelação & $5009706-88.2015 .4 .04 .7002$ & Terceiro grupo \\
\hline Apelação & $5000961-48.2013 .4 .04 .7016$ & Primeiro grupo \\
\hline Apelação & $5000030-30.2013 .4 .04 .7118$ & Primeiro grupo \\
\hline Apelação & $5006462-54.2015 .4 .04 .7002$ & Terceiro grupo \\
\hline Apelação & $5006929-24.2015 .4 .04 .7005$ & Primeiro grupo \\
\hline Apelação & 5000903-08.2014.4.04.7017 & Primeiro grupo \\
\hline Apelação & $5007847-37.2015 .4 .04 .7002$ & Primeiro grupo \\
\hline Apelação & 5000009-63.2017.4.04.7005 & Terceiro grupo \\
\hline Apelação & 5002229-14.2015.4.04.7002 & Terceiro grupo \\
\hline Apelação & $5003764-68.2012 .4 .04 .7006$ & Primeiro grupo \\
\hline
\end{tabular}




\begin{tabular}{|c|c|c|}
\hline Classe & Número do processo & Classificação \\
\hline Apelação & $5000418-82.2016 .4 .04 .7002$ & Terceiro grupo \\
\hline Apelação & $5006146-32.2015 .4 .04 .7005$ & Terceiro grupo \\
\hline Apelação & $5001503-96.2013 .4 .04 .7103$ & Primeiro grupo \\
\hline Apelação & $5001138-89.2015 .4 .04 .7000$ & Primeiro grupo \\
\hline Apelação & $5016117-91.2013 .4 .04 .7205$ & Terceiro grupo \\
\hline Apelação & 5083351-89.2014.4.04.7000 & Primeiro grupo \\
\hline Apelação & 5006235-55.2015.4.04.7005 & Terceiro grupo \\
\hline Apelação & 5012331-04.2015.4.04.7000 & Primeiro grupo \\
\hline Apelação & $5001367-52.2016 .4 .04 .7117$ & Terceiro grupo \\
\hline Apelação & $5000017-40.2017 .4 .04 .7005$ & Terceiro grupo \\
\hline Apelação & 5007371-33.2014.4.04.7002 & Terceiro grupo \\
\hline Apelação & 5008104-04.2016.4.04.7107 & Terceiro grupo \\
\hline Apelação & 5001136-94.2012.4.04.7010 & Terceiro grupo \\
\hline Apelação & 0001163-98.2008.4.04.7012 & Terceiro grupo \\
\hline Apelação & $5001678-57.2013 .4 .04 .7017$ & Primeiro grupo \\
\hline Apelação & 5010149-93.2016.4.04.7102 & Primeiro grupo \\
\hline Apelação & 5001073-44.2013.4.04.7007 & Terceiro grupo \\
\hline Apelação & 5001473-15.2014.4.04.7010 & Primeiro grupo \\
\hline Apelação & 5000691-66.2013.4.04.7002 & Terceiro grupo \\
\hline Apelação & 5005496-62.2013.4.04.7002 & Primeiro grupo \\
\hline Apelação & 5083401-18.2014.4.04.7000 & Primeiro grupo \\
\hline Apelação & 5019584-45.2012.4.04.7001 & Terceiro grupo \\
\hline Apelação & $5001511-74.2012 .4 .04 .7017$ & Terceiro grupo \\
\hline Apelação & $5002660-83.2013 .4 .04 .7013$ & Terceiro grupo \\
\hline Apelação & $5015478-66.2014 .4 .04 .7002$ & Terceiro grupo \\
\hline Apelação & $5032857-56.2010 .4 .04 .7100$ & Primeiro grupo \\
\hline $\begin{array}{c}\text { Recurso em } \\
\text { sentido estrito }\end{array}$ & 5002943-03.2017.4.04.7002 & Terceiro grupo \\
\hline Apelação & 5002214-81.2016.4.04.7205 & Terceiro grupo \\
\hline Apelação & 5007052-94.2016.4.04.7002 & Terceiro grupo \\
\hline Apelação & 5007730-46.2015.4.04.7002 & Terceiro grupo \\
\hline Apelação & 5007131-10.2015.4.04.7002 & Terceiro grupo \\
\hline Apelação & 5006229-76.2014.4.04.7007 & Primeiro grupo \\
\hline Apelação & 5023135-31.2015.4.04.7000 & Primeiro grupo \\
\hline Apelação & 5000543-78.2015.4.04.7004 & Terceiro grupo \\
\hline Apelação & 5002035-08.2011.4.04.7017 & Primeiro grupo \\
\hline Apelação & 5005531-06.2015.4.04.7114 & Terceiro grupo \\
\hline Apelação & $5065544-85.2016 .4 .04 .7000$ & Primeiro grupo \\
\hline
\end{tabular}




\begin{tabular}{|c|c|c|}
\hline Classe & Número do processo & Classificação \\
\hline Apelação & $5065544-85.2016 .4 .04 .7000$ & Primeiro grupo \\
\hline Apelação & 5004289-48.2015.4.04.7102 & Terceiro grupo \\
\hline Apelação & $5045241-84.2015 .4 .04 .7000$ & Primeiro grupo \\
\hline Apelação & 5006103-83.2015.4.04.7009 & Terceiro grupo \\
\hline Apelação & 5007069-33.2016.4.04.7002 & Primeiro grupo \\
\hline Apelação & 5000906-71.2015.4.04.7002 & Terceiro grupo \\
\hline Apelação & $5000674-85.2013 .4 .04 .7210$ & Primeiro grupo \\
\hline Apelação & 5016979-69.2016.4.04.7201 & Terceiro grupo \\
\hline Apelação & 5001637-67.2015.4.04.7002 & Primeiro grupo \\
\hline Apelação & $5001666-83.2016 .4 .04 .7002$ & Terceiro grupo \\
\hline Apelação & $5002267-74.2016 .4 .04 .7007$ & Primeiro grupo \\
\hline Apelação & $5007271-36.2014 .4 .04 .7210$ & Terceiro grupo \\
\hline Apelação & 5029841-93.2016.4.04.7000 & Terceiro grupo \\
\hline Apelação & $5083360-51.2014 .4 .04 .7000$ & Primeiro grupo \\
\hline Apelação & 5013405-59.2016.4.04.7000 & Primeiro grupo \\
\hline Apelação & $5004224-82.2017 .4 .04 .7005$ & Terceiro grupo \\
\hline Apelação & $5003685-09.2014 .4 .04 .7010$ & Terceiro grupo \\
\hline Apelação & $5002720-60.2016 .4 .04 .7010$ & Terceiro grupo \\
\hline Apelação & 5000863-60.2017.4.04.7101 & Terceiro grupo \\
\hline Apelação & 5002053-11.2010.4.04.7002 & Primeiro grupo \\
\hline Apelação & 5005765-22.2014.4.04.7114 & Terceiro grupo \\
\hline Apelação & $5001812-33.2017 .4 .04 .7118$ & Terceiro grupo \\
\hline Apelação & $5002385-59.2016 .4 .04 .7004$ & Terceiro grupo \\
\hline Apelação & $5012591-75.2015 .4 .04 .7002$ & Terceiro grupo \\
\hline Apelação & $5001220-65.2016 .4 .04 .7007$ & Primeiro grupo \\
\hline Apelação & $5011507-55.2014 .4 .04 .7202$ & Primeiro grupo \\
\hline Apelação & $5000697-73.2013 .4 .04 .7002$ & Terceiro grupo \\
\hline Apelação & $5046512-94.2016 .4 .04 .7000$ & Terceiro grupo \\
\hline Apelação & $5001808-55.2015 .4 .04 .7121$ & Primeiro grupo \\
\hline Apelação & 5004739-23.2017.4.04.7004 & Primeiro grupo \\
\hline Apelação & $5003830-31.2010 .4 .04 .7002$ & Terceiro grupo \\
\hline Apelação & $5064538-05.2014 .4 .04 .7100$ & Primeiro grupo \\
\hline Apelação & 5000944-25.2011.4.04.7002 & Terceiro grupo \\
\hline Apelação & $5003225-85.2010 .4 .04 .7002$ & Primeiro grupo \\
\hline Apelação & 5003161-02.2015.4.04.7002 & Terceiro grupo \\
\hline Apelação & 0001276-71.2007.4.04.7211 & Terceiro grupo \\
\hline Apelação & $5011799-59.2017 .4 .04 .7000$ & Terceiro grupo \\
\hline Apelação & $5004941-40.2016 .4 .04 .7002$ & Primeiro grupo \\
\hline
\end{tabular}




\begin{tabular}{|c|c|c|}
\hline Classe & Número do processo & Classificação \\
\hline Apelação & 5008299-13.2016.4.04.7002 & Terceiro grupo \\
\hline Apelação & $5011489-84.2016 .4 .04 .7001$ & Terceiro grupo \\
\hline Apelação & 5011289-74.2016.4.04.7002 & Terceiro grupo \\
\hline Apelação & 5011289-74.2016.4.04.7002 & Terceiro grupo \\
\hline Apelação & 5000920-34.2015.4.04.7106 & Primeiro grupo \\
\hline Apelação & $5001707-41.2016 .4 .04 .7005$ & Primeiro grupo \\
\hline Apelação & $5001162-84.2015 .4 .04 .7011$ & Terceiro grupo \\
\hline Apelação & 5008139-19.2015.4.04.7003 & Terceiro grupo \\
\hline Apelação & $5000472-27.2017 .4 .04 .7127$ & Primeiro grupo \\
\hline Apelação & 5005154-31.2016.4.04.7007 & Primeiro grupo \\
\hline Apelação & $5022182-33.2016 .4 .04 .7000$ & Primeiro grupo \\
\hline Apelação & $5042237-40.2014 .4 .04 .7108$ & Terceiro grupo \\
\hline Apelação & $5001608-04.2017 .4 .04 .7113$ & Terceiro grupo \\
\hline Apelação & $5000511-30.2016 .4 .04 .7007$ & Terceiro grupo \\
\hline Apelação & 5001055-85.2016.4.04.7017 & Terceiro grupo \\
\hline Apelação & 5003264-03.2015.4.04.7004 & Primeiro grupo \\
\hline Apelação & $5003180-55.2013 .4 .04 .7009$ & Terceiro grupo \\
\hline Apelação & 5004920-30.2017.4.04.7002 & Terceiro grupo \\
\hline Apelação & 5012841-11.2015.4.04.7002 & Terceiro grupo \\
\hline Apelação & 5000106-27.2017.4.04.7017 & Primeiro grupo \\
\hline Apelação & 5060482-94.2012.4.04.7100 & Primeiro grupo \\
\hline Apelação & 5028740-71.2014.4.04.7200 & Terceiro grupo \\
\hline Apelação & $5001071-82.2015 .4 .04 .7014$ & Terceiro grupo \\
\hline Apelação & $5005184-02.2017 .4 .04 .7114$ & Primeiro grupo \\
\hline Apelação & 5001343-69.2016.4.04.7005 & Terceiro grupo \\
\hline Apelação & 5003811-09.2016.4.04.7004 & Terceiro grupo \\
\hline Apelação & $5017469-49.2015 .4 .04 .7000$ & Terceiro grupo \\
\hline Apelação & 5001009-41.2016.4.04.7100 & Terceiro grupo \\
\hline Apelação & 5004170-17.2016.4.04.7114 & Primeiro grupo \\
\hline Apelação & 5001740-92.2016.4.04.7017 & Terceiro grupo \\
\hline Apelação & $5015046-39.2017 .4 .04 .7003$ & Terceiro grupo \\
\hline Apelação & $5006671-84.2010 .4 .04 .7200$ & Primeiro grupo \\
\hline Apelação & 5001602-18.2013.4.04.7216 & Terceiro grupo \\
\hline Apelação & $5005637-76.2016 .4 .04 .7002$ & Terceiro grupo \\
\hline Apelação & $5001677-67.2016 .4 .04 .7017$ & Primeiro grupo \\
\hline Apelação & 5063271-36.2016.4.04.7000 & Primeiro grupo \\
\hline Apelação & $5002836-57.2011 .4 .04 .7005$ & Terceiro grupo \\
\hline Apelação & $5002317-91.2011 .4 .04 .7002$ & Primeiro grupo \\
\hline
\end{tabular}




\begin{tabular}{|c|c|c|}
\hline Classe & Número do processo & Classificação \\
\hline Apelação & 5003309-44.2015.4.04.7121 & Primeiro grupo \\
\hline Apelação & $5006693-46.2013 .4 .04 .7004$ & Primeiro grupo \\
\hline Apelação & 5001031-91.2015.4.04.7017 & Terceiro grupo \\
\hline Apelação & 5001734-85.2016.4.04.7017 & Primeiro grupo \\
\hline Apelação & $5006044-39.2017 .4 .04 .7005$ & Primeiro grupo \\
\hline Apelação & 5001974-22.2016.4.04.7002 & Primeiro grupo \\
\hline Apelação & $5000050-91.2017 .4 .04 .7017$ & Terceiro grupo \\
\hline Apelação & $5002028-70.2016 .4 .04 .7007$ & Primeiro grupo \\
\hline Apelação & $5012461-90.2012 .4 .04 .7002$ & Terceiro grupo \\
\hline Apelação & $5000132-91.2018 .4 .04 .7016$ & Primeiro grupo \\
\hline Apelação & 5006627-24.2017.4.04.7005 & Terceiro grupo \\
\hline Apelação & 5000275-09.2015.4.04.7203 & Primeiro grupo \\
\hline Apelação & 5001088-39.2011.4.04.7118 & Primeiro grupo \\
\hline Apelação & 5001761-34.2017.4.04.7017 & Terceiro grupo \\
\hline Apelação & $5000121-69.2016 .4 .04 .7004$ & Terceiro grupo \\
\hline Apelação & $5004766-46.2016 .4 .04 .7002$ & Primeiro grupo \\
\hline Apelação & $5001962-36.2011 .4 .04 .7114$ & Terceiro grupo \\
\hline Apelação & $5024827-27.2013 .4 .04 .7100$ & Terceiro grupo \\
\hline Apelação & $5024827-27.2013 .4 .04 .7100$ & Terceiro grupo \\
\hline Apelação & 5005624-33.2014.4.04.7007 & Terceiro grupo \\
\hline Apelação & $5005232-94.2017 .4 .04 .7005$ & Terceiro grupo \\
\hline Apelação & 5008480-14.2016.4.04.7002 & Terceiro grupo \\
\hline Apelação & $5006974-57.2017 .4 .04 .7005$ & Terceiro grupo \\
\hline Apelação & $5027685-35.2016 .4 .04 .7000$ & Primeiro grupo \\
\hline Apelação & 5000270-65.2016.4.04.7004 & Terceiro grupo \\
\hline Apelação & $5004966-81.2015 .4 .04 .7004$ & Terceiro grupo \\
\hline Apelação & 5004261-34.2016.4.04.7009 & Terceiro grupo \\
\hline Apelação & 5006606-19.2015.4.04.7005 & Terceiro grupo \\
\hline Apelação & $5013789-79.2017 .4 .04 .7002$ & Primeiro grupo \\
\hline Apelação & $5005456-26.2017 .4 .04 .7201$ & Terceiro grupo \\
\hline Apelação & $5000231-87.2015 .4 .04 .7009$ & Primeiro grupo \\
\hline Apelação & 5006090-62.2016.4.04.7005 & Terceiro grupo \\
\hline Apelação & $5007220-69.2016 .4 .04 .7205$ & Terceiro grupo \\
\hline Apelação & 5028335-64.2016.4.04.7200 & Terceiro grupo \\
\hline Apelação & 5008960-26.2015.4.04.7002 & Primeiro grupo \\
\hline Apelação & $5000202-78.2017 .4 .04 .7005$ & Terceiro grupo \\
\hline Apelação & $5001111-42.2016 .4 .04 .7010$ & Primeiro grupo \\
\hline Apelação & $5008960-26.2015 .4 .04 .7002$ & Primeiro grupo \\
\hline
\end{tabular}




\begin{tabular}{|c|c|c|}
\hline Classe & Número do processo & Classificação \\
\hline Apelação & $5003274-53.2015 .4 .04 .7002$ & Primeiro grupo \\
\hline Apelação & 5004189-35.2016.4.04.7207 & Primeiro grupo \\
\hline Apelação & 5021693-61.2014.4.04.7001 & Primeiro grupo \\
\hline Apelação & 5001521-18.2016.4.04.7005 & Terceiro grupo \\
\hline Apelação & $5012137-32.2014 .4 .04 .7002$ & Terceiro grupo \\
\hline Apelação & $5001163-73.2018 .4 .04 .7202$ & Terceiro grupo \\
\hline Apelação & $5001737-92.2015 .4 .04 .7011$ & Terceiro grupo \\
\hline Apelação & 5001933-74.2015.4.04.7007 & Primeiro grupo \\
\hline Apelação & 5005724-98.2013.4.04.7111 & Primeiro grupo \\
\hline Apelação & $5006737-96.2012 .4 .04 .7005$ & Terceiro grupo \\
\hline Apelação & 5002645-66.2017.4.04.7113 & Primeiro grupo \\
\hline Apelação & $5030883-80.2016 .4 .04 .7000$ & Primeiro grupo \\
\hline Apelação & 5000714-07.2016.4.04.7002 & Primeiro grupo \\
\hline Apelação & 5002243-96.2014.4.04.7110 & Primeiro grupo \\
\hline Apelação & 5005264-95.2014.4.04.7008 & Terceiro grupo \\
\hline Apelação & 5001400-62.2017.4.04.7002 & Primeiro grupo \\
\hline Apelação & $5003685-50.2016 .4 .04 .7103$ & Primeiro grupo \\
\hline Apelação & $5000535-67.2016 .4 .04 .7004$ & Terceiro grupo \\
\hline Apelação & 5003045-25.2017.4.04.7002 & Terceiro grupo \\
\hline Apelação & $0000760-77.2009 .4 .04 .7115$ & Terceiro grupo \\
\hline Apelação & $5007887-48.2017 .4 .04 .7002$ & Terceiro grupo \\
\hline Apelação & 5015643-16.2014.4.04.7002 & Terceiro grupo \\
\hline Apelação & $5016382-86.2014 .4 .04 .7002$ & Terceiro grupo \\
\hline Apelação & 5000699-92.2017.4.04.7005 & Terceiro grupo \\
\hline Apelação & $5000687-87.2017 .4 .04 .7002$ & Terceiro grupo \\
\hline Apelação & 5000405-77.2016.4.04.7004 & Terceiro grupo \\
\hline Apelação & $5004005-72.2017 .4 .04 .7101$ & Terceiro grupo \\
\hline Apelação & 5002110-48.2014.4.04.7015 & Terceiro grupo \\
\hline Apelação & 5006335-14.2018.4.04.7002 & Primeiro grupo \\
\hline Apelação & 5035863-70.2016.4.04.7000 & Terceiro grupo \\
\hline Apelação & 5004933-29.2017.4.04.7002 & Terceiro grupo \\
\hline Apelação & $5001269-85.2011 .4 .04 .7103$ & Terceiro grupo \\
\hline Apelação & 5002598-92.2017.4.04.7016 & Terceiro grupo \\
\hline Apelação & $5004510-75.2013 .4 .04 .7013$ & Terceiro grupo \\
\hline Apelação & 5003491-87.2015.4.04.7005 & Terceiro grupo \\
\hline Apelação & 5001666-05.2015.4.04.7007 & Terceiro grupo \\
\hline Apelação & $5010200-91.2013 .4 .04 .7205$ & Terceiro grupo \\
\hline Apelação & $5005085-68.2017 .4 .04 .7005$ & Primeiro grupo \\
\hline
\end{tabular}




\begin{tabular}{|c|c|c|}
\hline Classe & Número do processo & Classificação \\
\hline Apelação & 5012854-10.2015.4.04.7002 & Terceiro grupo \\
\hline Apelação & 5000304-57.2018.4.04.7202 & Terceiro grupo \\
\hline Apelação & $5063918-31.2016 .4 .04 .7000$ & Primeiro grupo \\
\hline Apelação & 5002833-93.2016.4.04.7016 & Primeiro grupo \\
\hline Apelação & 5054932-88.2016.4.04.7000 & Terceiro grupo \\
\hline Apelação & $5001074-55.2015 .4 .04 .7202$ & Terceiro grupo \\
\hline Apelação & 5001610-68.2017.4.04.7017 & Terceiro grupo \\
\hline Apelação & 5000569-33.2017.4.04.7028 & Terceiro grupo \\
\hline Apelação & 5009859-19.2018.4.04.7002 & Terceiro grupo \\
\hline Apelação & 5006561-98.2014.4.04.7118 & Terceiro grupo \\
\hline Apelação & 5009424-82.2017.4.04.7001 & Terceiro grupo \\
\hline Apelação & 5004484-50.2017.4.04.7009 & Terceiro grupo \\
\hline Apelação & $5002345-70.2018 .4 .04 .7113$ & Terceiro grupo \\
\hline Apelação & 5002769-51.2018.4.04.7004 & Terceiro grupo \\
\hline Apelação & 5010703-08.2014.4.04.7002 & Primeiro grupo \\
\hline Apelação & 5018688-20.2017.4.04.7100 & Terceiro grupo \\
\hline Apelação & 5002849-86.2016.4.04.7100 & Terceiro grupo \\
\hline Apelação & 5012465-54.2017.4.04.7002 & Primeiro grupo \\
\hline Apelação & 5002776-51.2016.4.04.7121 & Terceiro grupo \\
\hline Apelação & $5003711-52.2015 .4 .04 .7016$ & Terceiro grupo \\
\hline Apelação & 5006187-65.2016.4.04.7004 & Terceiro grupo \\
\hline Apelação & 5001937-71.2016.4.04.7009 & Terceiro grupo \\
\hline Apelação & 5016216-34.2017.4.04.7201 & Terceiro grupo \\
\hline Apelação & 5002629-98.2015.4.04.7011 & Terceiro grupo \\
\hline Apelação & $5001880-29.2016 .4 .04 .7017$ & Terceiro grupo \\
\hline Apelação & 5002435-19.2015.4.04.7005 & Primeiro grupo \\
\hline Apelação & 5028101-66.2017.4.04.7000 & Terceiro grupo \\
\hline Apelação & 5001299-17.2016.4.04.7016 & Primeiro grupo \\
\hline Apelação & 5007524-20.2015.4.04.7200 & Terceiro grupo \\
\hline Apelação & $5010718-40.2015 .4 .04 .7002$ & Terceiro grupo \\
\hline Apelação & 5001190-45.2016.4.04.7002 & Terceiro grupo \\
\hline Apelação & 5011119-64.2014.4.04.7005 & Primeiro grupo \\
\hline Apelação & 5000802-51.2017.4.04.7118 & Primeiro grupo \\
\hline Apelação & 5010184-62.2016.4.04.7002 & Terceiro grupo \\
\hline Apelação & 5014134-45.2017.4.04.7002 & Terceiro grupo \\
\hline Apelação & $5005648-62.2017 .4 .04 .7005$ & Primeiro grupo \\
\hline Apelação & 5004565-83.2018.4.04.7002 & Terceiro grupo \\
\hline Apelação & $5001238-22.2017 .4 .04 .7017$ & Terceiro grupo \\
\hline
\end{tabular}




\begin{tabular}{|c|c|c|}
\hline Classe & Número do processo & Classificação \\
\hline Apelação & 5010545-79.2016.4.04.7002 & Primeiro grupo \\
\hline Apelação & 5009829-81.2018.4.04.7002 & Primeiro grupo \\
\hline Apelação & 5002142-14.2013.4.04.7104 & Primeiro grupo \\
\hline Apelação & $5005783-83.2017 .4 .04 .7002$ & Primeiro grupo \\
\hline Apelação & 5000802-55.2010.4.04.7002 & Terceiro grupo \\
\hline Apelação & 5005725-17.2016.4.04.7002 & Primeiro grupo \\
\hline Apelação & $5001953-75.2018 .4 .04 .7002$ & Primeiro grupo \\
\hline Apelação & 5006804-31.2016.4.04.7002 & Primeiro grupo \\
\hline Apelação & 5008924-09.2014.4.04.7102 & Primeiro grupo \\
\hline Apelação & $5000631-20.2018 .4 .04 .7002$ & Terceiro grupo \\
\hline Apelação & 5007489-29.2016.4.04.7005 & Terceiro grupo \\
\hline Apelação & 5001137-87.2018.4.04.7004 & Terceiro grupo \\
\hline Apelação & 5013184-77.2015.4.04.7108 & Primeiro grupo \\
\hline Apelação & $5005047-61.2014 .4 .04 .7102$ & Terceiro grupo \\
\hline Apelação & 5004912-13.2018.4.04.7004 & Terceiro grupo \\
\hline Apelação & 5014170-93.2017.4.04.7000 & Primeiro grupo \\
\hline Apelação & 5001017-05.2018.4.04.7017 & Terceiro grupo \\
\hline Apelação & 5000830-31.2017.4.04.7017 & Terceiro grupo \\
\hline Apelação & 5009270-92.2016.4.04.7003 & Terceiro grupo \\
\hline Apelação & $5001922-84.2017 .4 .04 .7133$ & Terceiro grupo \\
\hline Apelação & 5005762-04.2017.4.04.7004 & Primeiro grupo \\
\hline Apelação & 5004619-16.2013.4.04.7005 & Terceiro grupo \\
\hline Apelação & 5029683-04.2017.4.04.7000 & Primeiro grupo \\
\hline Apelação & 5001524-18.2018.4.04.7032 & Terceiro grupo \\
\hline Apelação & 5002372-87.2017.4.04.7113 & Terceiro grupo \\
\hline Apelação & 5005300-81.2016.4.04.7004 & Terceiro grupo \\
\hline Apelação & $5005796-82.2017 .4 .04 .7002$ & Terceiro grupo \\
\hline Apelação & 5001124-83.2017.4.04.7017 & Terceiro grupo \\
\hline
\end{tabular}

